\title{
Experimental study on seismic performance of post-fire reinforced concrete frames
}

DOI:

10.1016/j.engstruct.2018.10.080

\section{Document Version}

Accepted author manuscript

Link to publication record in Manchester Research Explorer

\section{Citation for published version (APA):}

Su, M-N., \& Xia, M. (2019). Experimental study on seismic performance of post-fire reinforced concrete frames. Engineering Structures. https://doi.org/10.1016/j.engstruct.2018.10.080

\section{Published in:}

Engineering Structures

\section{Citing this paper}

Please note that where the full-text provided on Manchester Research Explorer is the Author Accepted Manuscript or Proof version this may differ from the final Published version. If citing, it is advised that you check and use the publisher's definitive version.

\section{General rights}

Copyright and moral rights for the publications made accessible in the Research Explorer are retained by the authors and/or other copyright owners and it is a condition of accessing publications that users recognise and abide by the legal requirements associated with these rights.

\section{Takedown policy}

If you believe that this document breaches copyright please refer to the University of Manchester's Takedown Procedures [http://man.ac.uk/04Y6Bo] or contact uml.scholarlycommunications@manchester.ac.uk providing relevant details, so we can investigate your claim.

\section{OPEN ACCESS}




\section{Experimental study on seismic performance of post-fire reinforced concrete}

\section{frames}

Ling-Zhi Li ${ }^{1}$, Xin Liu ${ }^{2}$, Jiang-Tao Yu ${ }^{3 *}$, Zhou-Dao Lu ${ }^{4}$, Mei-Ni Su ${ }^{5}$, Jie-Hong Liao ${ }^{6}$, Min Xia ${ }^{7}$

${ }^{1}$ Title: Associate Professor

E-mail: tjlilingzhi@gmail.com

${ }^{2}$ Title: PhD Candidate

E-mail: 1x900314@126.com

3* Corresponding author:

Title: Associate Professor

E-mail: yujiangtao@gmail.com

${ }^{4}$ Title: Professor

E-mail: 1zd@tongji.edu.cn

${ }^{5}$ Title: Lecturer

E-mail:meini.su@manchester.ac.uk

${ }^{6}$ Title: Engineer

E-mail: liaojiehong@yahoo.cn

${ }^{7}$ Title: Associate Professor

E-mail: xiamin_chj@163.com

1,2,3,4 Address: Department of Disaster Mitigation for Structures, College of Civil Engineering, Tongji University, 1239 Siping Road, Shanghai 200092, China

${ }^{5}$ Address: School of Mechanical, Aerospace and Civil Engineering, University of Manchester, Manchester, UK, M1 3NJ

${ }^{6}$ Address: Hubei Wuda Luojia Inspection and Consultation of Engineering Structure Co. Ltd. 15F, Jucheng Building, 4 Wudayuan Road, Wuhan, Hubei, China

${ }^{7}$ Address: School of Civil Engineering, Suzhou University of Science and Technology, Suzhou 215011,China 
41 To investigate the post-fire seismic behaviour of reinforced concrete (RC) frames with different columnto-beam bending capacity ratios, four specimens were fabricated, which included a strong-beam-weakcolumn frame and a strong-column-weak-beam frame either under room temperature or after being exposed to fire. The fire test was conducted in a furnace chamber, followed by quasi-static tests under a low-frequency cyclic load. The crack patterns, hysteretic loops, plastic hinges, and failure modes were investigated in the loading process. The influence of two factors, i.e., the fire exposure and the columnto-beam bending capacity ratio, on the mechanical performance, ductility, stiffness degradation, and energy dissipation was compared and analysed. The experimental results indicated that the ultimate bearing capacity, the stiffness, the ductility factor, and the energy dissipation capacity of the RC frames decreased after fire exposure. The bearing capacity of the strong-beam-weak-column frame decreased even more seriously. Although the yielding displacements of the post-fire frames increased, their ultimate displacements decreased. In addition, the strong-column-weak-beam frame under room temperature failed in the form of beam-end plastic hinging, while after being exposed to fire, the failure mode changed to shear-bond failure in column.

\section{Keywords:}

Reinforced concrete (RC) frame; Post-fire; Seismic performance; Bearing capacity; Stiffness 


\section{Introduction}

Reinforced concrete (RC) frame structures constructed prior to 1980 s generally do not meet the requirements of seismic design code in mainland China [1] due to the deficient design which only took gravity loads into consideration and ignored the lateral actions such as earthquake and winds. For instance, some old buildings were designed as sub-standard RC frames with strong beams but weak columns, which might result in harmful brittle failures such as joint shearing and column hinging. In addition, building fire is one of the most frequent disasters that will happen in RC buildings. Although the post-fire RC frames can generally be retrofitted using proper strengthening techniques such as enlarging of joint area [2, 3], adhesive bonding or near surface mounting [4-6] of fibre reinforced polymers (FRP), bonding or anchoring of steel plates [7-9], etc. they may encounter an earthquake attack in their subsequent post-fire service life thus fail and even collapse. Therefore, for these sub-standard $\mathrm{RC}$ frames, not only the researches on their residual bearing capacity is necessary, but also those focusing on their post-fire seismic performance is of great significance.

Most existing studies mainly focused on the post-fire performance of concrete/steel materials and $\mathrm{RC}$ members rather than the behaviour of RC structures. Numerous investigations were conducted to study the residual mechanical properties of concrete and reinforcing steel, as well as the bond-slip of steel-concrete interface after exposure to fire. It was found that the compressive strength and elasticity modulus of concrete $[10,11]$, the deformability, yield strength and ultimate strength of reinforcing steel $[12,13]$, as well as the steel-concrete bond strength $[14,15]$ would be affected significantly by

high temperatures. Similarly, as regarding to studies on the residual post-fire mechanical performance of RC beams [16-18], columns [19, 20] and slabs [21, 22], researchers found that the bearing capacity of these RC members were deteriorated by elevated temperatures, and the deterioration increased with fire exposure time.

However, although there are many research findings on the post-fire mechanical properties of RC beams, columns and slabs, the structural response of a statically indeterminate frame structure in fire is much different from and more complicated than those of a single beam, column or slab, thus cannot be deduced by the research outcomes of these structural members. Firstly, the temperature caused by fire 
does not distribute uniformly between different frame components, resulting in the increasing inconsistency of stress distribution. Vecchio and Sato [23] tested three RC portal frames under combinations of thermal and mechanical loads, and found that thermal loads resulted in significant stress thus lead to concentrated damage in local regions. Law et al. [24] developed a methodology for defining a family of possible heating regimes to an RC frame using the concept of travelling fires, and found in addition to the influence of uneven heating and temperature fields, strong interactions exist among heated members and their adjoining unheated members in a frame under fire, due to thermal expansion and large deformation of the heated members. Secondly, in the investigation of beams, columns and slabs, the standard fire test [25] following ISO 834 temperature curve has been the predominant means, which always suffers the problem of using isolated single members under unrealistic temperature-time curves to simulate real structural performance in a realistic fire. To overcome this shortcoming, researchers developed non-standard fire tests [26, 27] for large-scale structural members and structures. A "crudeness framework" [26] was also proposed to categorize fire tests with respect to the levels of complexities of both the fire and the structural models used in testing, and the tests close to the diagonal line connecting the standard fire test and the real fire was considered as the most defensible from a consistent crudeness perspective.

On the other hand, studies on the structural aspect, i.e. the post-fire residual load-bearing capacity of RC frames, also have been carried out. Raouffardand and Nishiyama [28] investigated the fire and post-fire responses of a two-story moment resisting RC frame, the results showed that the mid-span deflection could considerably recovered due to the strength recovery of the reinforcement, and the bearing capacity reduction caused by fire damage was up to 30\%. Zhang et al. [29] tested nine post-fire RC frames under static loads, the results showed that the effects of fire temperature on the mechanical properties of the frame was larger than the fire load. Furthermore, the bearing capacity decreased to $57.3 \%$ when the temperature exceeded $1000{ }^{\circ} \mathrm{C}$. Xia et al. [30] proposed a fibre element model based on ABAQUS to analyse the residual bearing capacity of three-dimensional (3D) RC frames after fire exposure, the numerical model considers the distribution of non-uniform temperature in the crosssections of structural members and the changing of mechanical properties of materials damaged by fire. 
However, studies on the post-fire seismic performance of RC frames are still very limited. Kamath,

115 Sharma and Shah $[31,32]$ designed a set of full-scale push-over and cyclic loading tests on seismically

116 damaged RC frames subsequently exposed to fire, the hysteretic response and envelope curves were 117 analyzed to assess the residual seismic capacity. The results showed that temperature distribution 118 throughout the compartment was non-uniform and the pre-damage level affected the rise in temperatures 119 in the structural elements; moreover, there was no large strength and stiffness degradation, no permanent 120 drifts and sign of collapse, thus the frame could withstand the mechanical damage and subsequent fire 121 without collapse. Xiao et al. [33] tested four single-span and single-story frames under low-frequency cyclic loads after being exposed to fire, the hysteretic behaviour, the stiffness degradation and energy dissipation were investigated; the post-fire seismic performance were also examined based on the fire test results. It was found that after a fire attack, the difference in stiffness degradations of beams and columns in an RC frame could transform the seismic failure mode from a strong-column-weak-beam failure into a strong-beam-weak-column one, which performed unsatisfactorily under cyclic loads. of 3D spatial frames in engineering practice. The 3D frames in real structures are always with slabs and orthogonal beams. This discrepancy might cause serious deficiency and unreliability, i.e., the experimental results could not reflect the actual conditions. In light of this situation, an experimental study will be reported in this paper, for which slabs and orthogonal beams will be taken into consideration in the fire test, and cyclical loading test will be employed to investigate the post-fire seismic performance of RC frames with different section sizes of beam and column components.

\section{Experimental program}

\subsection{Specimen details}

138 In order to simplify the calculation and stress analysis, the analysis of a standard planar frame was 139 usually used to replace that of a spatial RC frame. In this study, a 3D frame were firstly adopted to 140 simulate the fire response of a real frame structure under fire. Due to the very limited test setup, planar 
141 frames were then isolated from the 3D frame to conduct the cyclic loading test.

Two 1/2 scaled spatial RC frames with slabs (as shown in Fig. 1(a)) were fabricated: one was unfired and employed as a reference, the other was fired in a furnace and then placed for weeks until all temperatures reached ambient to investigate the post-fire behaviour. Two planar frames were then cut off from the unfired and fired spatial frames for the subsequent cyclic loading test, by removing the whole slab and orthogonal beams, as shown in Fig. 1(b). During the removing process, none micro cracks and deflection were found, thus the influence of the cutting work to the mechanical behaviour of the test frames was ignored. The planar frames cut from the unfired spatial frame were named as SBF and SCF, while those cut from the fire-damaged one were named as SBFT and SCFT, where the first three letters "SBF" represent "Strong-Beam Frame", the "SCF" represents "Strong-Column Frame", and the last letter " $\mathrm{T} "$ indicates exposure to elevated temperature.

According to the current seismic design code in mainland China [1], the ratio between the bending moments on the column and beam end sections of frame joints $\left(\eta=M_{\mathrm{c}} / M_{\mathrm{b}}\right)$ should be greater than 1.3 for Grade III frames, which are suitable for the majority proportion of frame structures in mainland China. The specimens SBF and SBFT were identical in dimension and reinforcement configuration, and they were in Strong-Beam-Weak-Column forms (the column-to-beam bending capacity ratio $\eta=0.7<<1.3)$ and employed as benchmarks representing the sub-standard frames according to pre1980s design codes in mainland China. Whereas the other two specimens SCF and SCFT were identical in dimension and reinforcement, and they were in Strong-Column-Weak-Beam forms $(\eta=1.6>1.3)$ and representing the standard $\mathrm{RC}$ frames following the current Chinese seismic code [1]. The 161 information of the four planar RC frames is presented in Table 1.

As is shown in Fig. 2(a)-(c), the length and height of the planar RC frames were $2350 \mathrm{~mm}$ and $1800 \mathrm{~mm}$, respectively. The cross-sectional size was $150 \mathrm{~mm} \times 350 \mathrm{~mm}$ for the beams in SBF and SBFT, and $120 \mathrm{~mm} \times 250 \mathrm{~mm}$ for those in SCF and SCFT; and the column size was $250 \mathrm{~mm} \times 250 \mathrm{~mm}$ for all. The longitudinal reinforcement used in the columns was $8 \mathrm{D} 16$, corresponding to a reinforcement ratio of $2.57 \%$. For the RC beams in SBF and SBFT, longitudinal reinforcements of 3D16 were placed at both the top and bottom sides, corresponding to a reinforcement ratio of $2.02 \%$; while for those in SCF 
and SCFT, the top and bottom longitudinal reinforcements were 2D14, corresponding to a reinforcement ratio of $1.03 \%$. The transverse reinforcements in the columns were a closed rectangular tie plus two unclosed ties, with a diameter of $6 \mathrm{~mm}$ and a spacing of $150 \mathrm{~mm}$ centre to centre (i.e., R6-150). While those in the RC beams were a closed rectangular tie of R6-150. The reinforcement details of beamcolumn connection region for all the frames are shown in Fig. 2(d)-(e), where the hook length of the $135^{\circ}$ hooked stirrup was $75 \mathrm{~mm}$ based on the requirements of the seismic design code in mainland China. In addition, according to this code, the $90^{\circ}$ hooked anchorage length of the deformed bar should be greater than $15 d$ (where $d$ was the diameter of the longitudinal reinforcement), thus the $90^{\circ}$ hooked anchorage length of the beam longitudinal rebar in SBF and SBFT was $240 \mathrm{~mm}$ while that in SCF and SCFT was $210 \mathrm{~mm}$. Similarly, the $90^{\circ}$ hooked anchorage length of the column longitudinal rebar for all the specimens was $200 \mathrm{~mm}$ according to the seismic design code, where it cannot be less than $12 d$. The cross-sectional dimensions and the reinforcement details for all the orthogonal beam were the same as the beams in SCF and SCFT, as shown in Fig. 2(g). The steel rebars in the floor slab were two-way twolayer with R6-150 as shown in Fig 2(f) \& (g). The thickness of the concrete cover was $15 \mathrm{~mm}$ with half of the figures compared to a full-scale specimen. The notations ' $D$ ' and ' $R$ ' denote the high-yield steel deformed bars and the mild steel round bars.

\subsection{Material properties}

Commercial ready-mixed concrete was chosen to cast all the specimens, and the mix proportion was shown in Table 2. Three concrete prisms with dimensions of $100 \mathrm{~mm} \times 100 \mathrm{~mm} \times 300 \mathrm{~mm}$ were cast and tested to obtain the material properties; the tested average compressive strength was $43.9 \mathrm{MPa}$.

Three bar samples with a length of $500 \mathrm{~mm}$ were taken from each type of reinforcements for tension tests to obtain the mechanical properties, as shown in Table 3.

\subsection{Test set-up and instrumentation}

This experimental study includes a fire test and a low-cyclic lateral loading test. The furnace chamber for the fire test has a floor area of $4000 \mathrm{~mm} \times 3000 \mathrm{~mm}$ and a height of $1800 \mathrm{~mm}$, as shown in Fig. 3(a). 
The spatial RC frame was placed in the furnace entirely with columns heated on all side faces, beams heated on tensile soffit and two side faces, and slab heated on the bottom face, respectively. To simulate the real stress condition of the RC structure in the target environment, a uniformly distributed load of $1 \mathrm{kN} / \mathrm{m}^{2}$ provided by mass blocks was imposed on the top surface of slab as illustrated in Fig. 3(b). The scale factor was $1 / 2$, corresponding to a live load of office and residential buildings $\left(2 \mathrm{kN} / \mathrm{m}^{2}\right)$ defined by the Chinese design code [1]. The schematic diagram of fire test is shown in Fig. 3(c), which exhibits the conceptual areas of the flames. Besides, a total of 15 WRNK-162S thermocouples were installed in the beam mid-span section and the column section to calibrate the temperature distribution under fire exposure, as shown in Fig. 3(d), where D represents the distance between the thermocouple and the bottom surface of the beam, or the outside surface of the column. For instance, D245 denotes that the distance between thermocouple and the beam bottom surface is $245 \mathrm{~mm}$, and D100 represents that the distance between thermocouple and the column outside surface is $100 \mathrm{~mm}$.

All the planar RC frames were tested under low-cyclic lateral loads in a reaction frame, and the general arrangement of the test setup is shown in Fig. 4. A preloading with approximately $10 \%$ of the estimated yielding strength was imposed on the horizontal beam to eliminate the initial stresses in the specimens and the possible malfunction or error of the instrument and data acquisition system. Each jack was installed in the same plane with the RC frame, and the loading protocol of the reversed cyclic loading test is shown in Fig. 5. The horizontal cyclic load was supplied by a $500 \mathrm{kN}$ MTS actuator, and the selected loading scheme consisted of two phases. The first phase was load-controlled and with one cycle per level, then the yielding displacement $\left(\Delta_{\mathrm{y}}\right)$ was recorded when the frame began to yield. The second phase of loading was displacement-controlled, composed of applying incremental multiples of the yielding displacement $\left(\Delta_{\mathrm{y}}\right)$ until the test was terminated, with three loading cycles per ductility level. Besides, both columns were imposed an axial load of $270 \mathrm{kN}$ at the top surfaces by two hydraulic jacks on the rigid distribution beam, which represented the gravity load and kept constant throughout the test. Furthermore, a movable slip roller was adopted between the reaction frame and the hydraulic jacks to reflect the boundary conditions and simulate the slipping bearing at the beam-column junction. A total of nine strain gauges were attached in the critical regions to obtain the strain values in longitudinal 
tensile reinforcements, stirrups and concrete. Three linear variable differential transducers (LVDTs) were placed at the mid-span of the beam, the half-height of the column, and the mid-span of the base beam to measure the longitudinal deformations along the loading direction. All measurements of load cells, displacement transducers and strain gauges were recorded by a computer data logger.

\section{Results and discussion of the fire experiment}

\subsection{Thermal response}

As can be seen from Fig. 6(a), the furnace temperature curve was lower than the ISO834 temperature curve due to two major reasons: (1) the heat insulation capacity of the slab plate was not enough due to the insufficient thickness $(60 \mathrm{~mm})$; (2) the insufficient heating capacity caused by the limitation of the furnace equipment such as gas burners and exhaust system. It should be noted that the role of fire in this study is to supply a high temperature scenario, cause permanent damage and degradation to concrete and steel materials, thus investigate the thermal response of an actual $\mathrm{RC}$ frame and then the post-fire seismic performance. So it was neither a real fire nor a standard test, and the defensibility of this nonstandard fire test can be verified by the "crudeness framework" [26]. Despite the differences between this actual fire test and the pre-determined ISO834 standard curve, the temperature field can be collected by the embed thermocouples, then the strength loss of concrete and reinforcement can be estimated under this specific condition.

It was also evident that the temperatures at the beam mid-span section A (as shown in Fig. 3) of SBFT and SCFT decrease as the increase of the embedded depth (for instance, D10 > D25 > D45 > D145 > D245). As shown in Fig 6(a), the temperature value at D10 is $690{ }^{\circ} \mathrm{C}$, which is close to that of the furnace $\left(746^{\circ} \mathrm{C}\right)$ at the time of flameout. Simultaneously the temperature at D245 is much lower $\left(317^{\circ} \mathrm{C}\right)$. As for the temperature of SCFT at beam mid-span (as shown in Fig. 6(b)), the value at D10 was $684^{\circ} \mathrm{C}$ and presents a negligible difference of $6{ }^{\circ} \mathrm{C}$ compared with that in SBFT $\left(690{ }^{\circ} \mathrm{C}\right)$, which indicates a satisfactory homogeneity of temperature in the furnace. The temperature at D100 was $337^{\circ} \mathrm{C}$ and lower than that at D10.

The temperature-time curves at the column section B (as shown in Fig. 3(c)) is illustrated in 
Fig. 6(c), whose temperature also decreases with the increasing embedded depth. Besides, the temperature at D10 in the column of SCFT was $606^{\circ} \mathrm{C}$, which exhibits a large difference compared to those at beam mid-span $\left(690^{\circ} \mathrm{C}\right.$ in SBFT and $684^{\circ} \mathrm{C}$ in SCFT), this phenomenon indicates that despite the homogeneous temperature in the furnace, the thermal distribution still has some discrepancy in different component.

According to the highest temperatures collected in the fire test and the existing research outcomes in literature [10-12] about the residual mechanical properties of concrete and steel materials, the reduction factor of yield strength of the longitudinal rebars near the fired surface was about $f_{\mathrm{y}}^{\mathrm{T}} / f_{\mathrm{y}}=0.88$

(where $f_{\mathrm{y}}$ and $f_{\mathrm{y}}^{\mathrm{T}}$ are the yield strength under ambient temperature and after fire, respectively). The reduction factors of concrete compressive strength at D10 of the beam mid-span of SCFT and SBFT, and the column half-height were $0.33,0.33$ and 0.44 respectively, which indicates the concrete cover almost lost all of its strength. While the reduction factors at D100 were $0.84,0.71$ and 0.87 respectively, which indicates a slight material degradation inside the beam and column members.

\subsection{Experimental phenomena under fire}

At the beginning of the fire test $(t=15 \mathrm{~min}$ ), a small amount of water stains appeared on the slab surface, where the temperature was about $50{ }^{\circ} \mathrm{C}$. With continuous increasing of the temperature $(t=30 \mathrm{~min})$, a large amount of water stains and water vapour emerged. When $t=50 \mathrm{~min}$, most of the moisture on the slab surface has evaporated, and the surface temperature reached $120^{\circ} \mathrm{C}$. The slab surface temperature was about $230^{\circ} \mathrm{C}$ at the flameout $(t=140 \mathrm{~min})$. Then the specimens were cooled naturally by air cooling via convection, as shown in Fig. 7(a). A large number of micro cracks appeared in the surface of all the components of the frame, and a large extent concrete spalling from the slab bottom surface, which caused the exposure of steel bars, as shown in Fig. 7(b) \& (c). The concrete spalling also increased the deflection of slab and made it concave significantly with annular cracks on the top surface along the periphery, as shown in Fig. 7(d). Since the floor slab and orthogonal beams in this study was only used to simulate the real structures in a fire, thus the slab spalling will not be further discussed hereafter. On the other hand, the deformation of the beam and column components were negligible. 


\section{Results and discussions of the quasi-static cyclic loading test}

In this section, based on the mechanical test of the unfired control specimens and the post-fire specimens, the comparisons of failure modes, distribution of cracks, force-displacement hysteretic response, secant stiffness, bearing capacity, ductility and energy dissipation capacity will be investigated.

\subsection{Failure modes}

Table 4 and Fig. 8 summarizes the failure modes of all the specimens. For the sub-standard frame tested under room temperature, i.e., SBF, the damage pattern of column shear occurred as shown in Fig. 8(a). The first diagonal crack appeared in the joint zone at a load of $90 \mathrm{kN}$ (corresponding to a drift of $0.34 \%$ ), followed by more cracks occurring on the beam and column surfaces close to the joint zone as loading progressed. These additional cracks finally developed into X-shaped cracks. At the displacementcontrolled stage, a large number of diagonal cracks emerged not only in the beam potential plastic hinging zone, but also in the column potential plastic hinging zone. At a drift of $2.67 \%$, a diagonal crack with a width of $2 \mathrm{~mm}$ appeared at the column face due to the shear force caused by the horizontal cyclical load, concrete in the shear-compression zone crushed. The test was terminated when the drift reached $3.20 \%$, and the width of the main diagonal crack was $10 \mathrm{~mm}$, which leads to the shear failure of column.

As can be seen in Fig. 8(b), there is a substantial difference between the post-fire sub-standard frame SBFT (where the column shear-bond failure occurred) and its unfired counterpart SBF in terms of failure mode. The first diagonal crack was observed on the column surface at the loading level of $60 \mathrm{kN}$ (corresponding to a drift of $0.47 \%$ ) and on the beam surface at the loading level of $90 \mathrm{kN}$ (a drift of $0.84 \%$ ), respectively. Dozens of cracks appeared near the edges of both columns along longitudinal rebars with the rising of the loads, and the increasing crack width leads to the peeling of concrete cover at a drift of $2.13 \%$. Finally, SBFT failed at a drift of $3.47 \%$ due to a combination effect of compression and shear, the concrete in shear-compression crushed accompanied with spalling of concrete cover. The change of failure mode shifting from column shear failure in SBF to column shear-bond failure in SBFT may be caused by the strength degradation of concrete after fire, which may make the column 
transformed from tension-controlled bending to compression-controlled bending condition.

For the unfired standard frame SCF, the first flexural crack emerged on the beam surface at a load of $120 \mathrm{kN}$ (a drift of $0.77 \%$ ), then diagonal shear cracks appeared as the cycle load increased to $160 \mathrm{kN}$. Furthermore, at a drift of $3.20 \%$, wide flexural and diagonal cracks developed in the beam-end due to the bending moment and shear caused by the cyclic force. Finally, as shown in Fig. 8(c), SCF failed in the form of beam-end plastic hinging at a drift of $4.41 \%$, corresponding to a loading level of $146 \mathrm{kN}$. This failure mode exhibited a satisfactory ductility and energy dissipation capacity.

However, the damage pattern of the post-fire standard frame SCFT changed substantially and became the column shear-bond failure, as shown in Fig. 8(d). Compared with SCF, the load of SCFT corresponding to the first crack decreased to $45 \mathrm{kN}$ (corresponding to a drift of $0.49 \%$ ) after the 140min exposure of fire, and the location of the first crack was observed at the beam-end surface. Then cracks appeared in the columns and their length, width and number propagated constantly as the loading progressed. In addition, compared with the value of former cycle load, an obvious lower load was detected when the column reached the same displacement, which known as strength degradation. Finally, SCFT failed in the columns due to a combination effect of compression and shear, the concrete in shearcompression crushed accompanied with spalling of concrete cover. The test was terminated at a drift of $4.41 \%$, corresponding to a load of $109 \mathrm{kN}$, as the bearing capacity significantly declined.

Fig. 8(e) summarizes the most seriously damaged parts (i.e. plastic hinges) of all the four specimens at the ultimate limit state. It is evident that the locations of failure were significantly changed due to fire exposure. For the frame SBF, the shear failure zone were mainly located at the column ends adjacent to the joint cores, while for the post-fire frame SBFT, the failure transferred to the whole length of columns and it was a brittle shear-bond failure. Similarly, the plastic hinging failure located at the beam ends of SCF shifted to the shear-bond failure in the whole length of columns in SCFT. The variations in the location and range of failure can be attributed as the main factors that changed the seismic performance of the fire-damaged frames. 
330 Since the force-displacement hysteretic response under cyclic loading reflects both the energy 331 dissipation efficiency and ductility ability, it is the most significant characteristic for the evaluation of 332

\subsection{Hysteretic behaviour of specimens} the seismic performance of a structural component. Therefore, the curves of force-displacement (and drift) hysteretic response are shown in Fig. 9 to investigate the seismic performances of all the specimens. The four graphs illustrate how the bearing capacity of the unfired and post-fire specimens changed at different drift. As for the specimens with strong beams, i.e., SBF and SBFT, there were substantial differences in not only the ultimate loads and drift, but also the energy dissipation capacity. Compared to the unfired SBF, the post-fire SBFT exhibited a much lower load value under a certain drift, and the hysteretic loops show remarkable pinching and considerable stiffness and strength degradation as the increasing of drift. As for the unfired specimen SCF with strong columns, there is no noticeable pinching in the hysteretic loops due to the ductile failure mode of beam-end plastic hinging, the ultimate load and stiffness are significantly larger than those of the post-fire specimen SCFT. The largest difference is in the areas of hysteretic loops per cycle, where the post-fire specimens had a serious degradation. In conclusion, all of these results indicate that the fire exposure decreased the seismic performance of RC frames to a certain degree.

\subsection{Envelope curves}

For all the specimens, the maximum load in the first cycle of each ductility level was recorded and plotted against the corresponding drift (see Fig. 10), which forms the force-displacement envelope curve of the tested frame in the displacement-controlled phase and can be used to investigate the development of the bearing capacity with the increasing displacements. It is evident from Fig. 10 that the ultimate loads of the post-fire frames SBFT $(164.5 \mathrm{kN})$ and SCFT $(154.2 \mathrm{kN})$ showed a downward trend compared with their unfired counterparts SBF $(262 \mathrm{kN})$ and SCF $(191.7 \mathrm{kN})$. Therefore, the reduction of the loading capacities of SBFT and SCFT were $37 \%$ and $20 \%$ compared to those of SBF and SCF, respectively, which indicates the bearing capacity decreased dramatically after exposure to fire. Furthermore, although the frames with strong beams (SBF \& SBFT) exhibited a higher bearing 
capacity under the same drift when compared to those with strong columns (SCF \& SCFT), they showed a much lower ultimate deformability. Overall, the sub-standard frames with strong beams but weak columns (which unsatisfied the current seismic design code) showed more strength loss and smaller ductility after being exposed to fire.

The definition of yielding deformation (displacement, rotation or curvature) always faced a difficulty since the force-displacement relation of RC components may not show a well-defined yielding point. To solve this problem and quantitatively analyse the ductility factor of the $\mathrm{RC}$ frames, an idealized bilinear force-displacement curve based on reduced stiffness equivalent elasto-plastic theory [34, 35] was introduced according to the shape of the envelope curves (see Fig. 11). The non-linear elastic behaviour before the first yielding or $0.75 P_{\mathrm{u}}$ is due to the cracking in the case of reinforced concrete. The intersecting point of the two branches was adopted to determine the yielding point $\left(P_{\mathrm{u}}, \Delta_{\mathrm{y}}\right)$ of the specimens, where the ascending branch connecting the coordinate origin and the point $\left(0.75 P_{\mathrm{u}}, \Delta_{\mathrm{y} 1}\right)$ on the envelope curve. The slope of this equivalent ascending branch is termed as the equivalent elastic stiffness $\left(K_{\mathrm{e}}\right)$ and employed to calibrate the stiffness of the frame under a static loading. When considering the definition of the ultimate deformation, it should be recognized that most structures have some capacities for deformation beyond the peak of the force-displacement relation without a significant reduction in strength, thus it would be reasonable to recognize part of this post-peak deformability. Therefore, the point on the post peak branch (where $P=0.8 P_{\mathrm{u}}$ ) was defined as the failure point, corresponding to the ultimate displacement $\left(\Delta_{\mathrm{u}}\right)$.

Ductility is a significant parameter to assess the seismic performance and usually expressed in terms of ductility factor $(\mu)$, which is computed as the ratio of the ultimate displacement $\left(\Delta_{\mathrm{u}}\right)$ to the yielding displacement $\left(\Delta_{\mathrm{y}}\right)$, as shown in Eq. (1).

$$
\mu=\frac{\Delta_{\mu}}{\Delta_{y}}
$$

The ultimate loads, yielding and ultimate displacements, ductility factors, and equivalent elastic stiffness of all the four specimens were computed from the envelope curves, which were listed in Table 4. The results showed that there is remarkable difference between the unfired and the post-fire frames in 
the ultimate loads, ductility and stiffness. An obvious decrease in the ultimate loads $\left(P_{\mathrm{u}}\right)$ can be found for the post-fire frames compared with their unfired counterparts, the reduction percentages for SBFT and SCFT were $37 \%$ and $20 \%$, respectively. In addition, the yielding displacements of the post-fire frames showed a substantial growth compared with their unfired counterparts (increased from $21.6 \mathrm{~mm}$ to $24.9 \mathrm{~mm}$ for SBFT, and from $20.4 \mathrm{~mm}$ to $34.0 \mathrm{~mm}$ for SCFT, respectively); the ultimate displacement exhibited a serious degradation for the frame with strong beams (decreased from $56.4 \mathrm{~mm}$ to $43.6 \mathrm{~mm}$ for SBFT), and remained at the same level for that with strong columns (increased from $58.9 \mathrm{~mm}$ to $59.1 \mathrm{~mm}$ for SCFT). There was significant degradation in the ductility factors $(\mu)$ of the post-fire frames, and the reduction percentages for SBFT and SCFT were $33 \%$ and $39 \%$, respectively. And the degradation in the equivalent elastic stiffness $\left(K_{\mathrm{e}}\right)$ was even more serious, and the reduction percentages for SBFT and SCFT were $45 \%$ and $51 \%$, respectively.

\subsection{Cyclic stiffness degradation}

As shown in Fig. 12, the cyclic secant stiffness can be represented by the slope of peak-to-peak stiffness at different hysteretic loops, as given by Eq. (2). To investigate and compare the degradation of the cyclic stiffness of all the frames, only the cyclic secant stiffness of the first reverse cycle in each ductility level is considered herein:

$$
k_{i}=\frac{F_{i}^{+}-F_{i}^{-}}{D_{i}^{+}-D_{i}^{-}}
$$

Where $k_{i}$ is the cyclic secant stiffness in each cycle. ${F_{i}}^{+}$and $F_{i}^{-}$are the peak loads at the positive and the negative loading directions, while $D_{i}^{+}$and $D_{i}^{-}$are the displacements corresponding to the peak loads $F_{i}^{+}$and $F_{i}^{-}$, respectively.

Fig. 13 shows the development of the cyclic secant stiffness of all the specimens at increasing drift. As can be seen, the cyclic secant stiffness decreased with the increase of displacement, and the degradation of cyclic stiffness might be caused by concrete cracking and the formation of plastic hinges. In addition, there was a large degradation in cyclic stiffness between SBFT and SBF due to the effect of fire exposure (decreased from $5.3 \mathrm{kN} / \mathrm{mm}$ to $2.4 \mathrm{kN} / \mathrm{mm}$ at a drift of $3.2 \%$ ); while as for SCF and SCFT, 
despite the large degradation in cyclic stiffness in the initial stage of loading, the difference became less significant after the drift was greater than $3.2 \%$ (decreased from $3.9 \mathrm{kN} / \mathrm{mm}$ to $3.3 \mathrm{kN} / \mathrm{mm}$ at a drift of 3.2\%). Furthermore, the cyclic stiffness of SBF and SBFT were larger than those of SCF and SCFT under the same stage of deformation. In conclusion, all these phenomena indicate that the cyclic stiffness would be degraded seriously after the frames being exposed to fire.

\subsection{Energy dissipation}

Energy dissipation capacity is one of the most important parameter to evaluate the seismic performance of a structure. It means the ability of a structure or component to consume seismic energy through its own plastic deformation under earthquake. Based on the analysis of the experimental phenomena and data, it is found that the total energy dissipation of an RC structure is composed of three main aspects the energy dissipated by the reinforcement, the friction of concrete cracks, and the formation of new concrete cracks [36]. The per cycle energy dissipation can be calculated by the area enclosed by a complete hysteretic loop and the coordinate axes in the force-displacement hysteretic curves as shown in Fig. 12, of which the background was shadowed with double line grille. The cumulative energy dissipation can be computed through the summation of areas enclosed by each hysteretic loops [37]. The development of the cumulative energies of all the specimens is presented in Fig. 14, and the energy per cycle for all the specimens is also given in Fig. 15.

As for the energy dissipation of all the specimens, there was a slightly growth before the drift reached $0.8 \%$. However, the cumulative energy for each specimen became larger and larger when the drift was greater than $0.8 \%$, the energy values of SBF, SCF, SBFT and SCFT were 22425, 19105, 12110, and $8217 \mathrm{kN} \cdot \mathrm{mm}$ at a drift of $3.2 \%$, respectively. The post-fire specimens dissipated less energy with respect to their corresponding unfired counterparts up to $-46 \%$ and $-57 \%$ for SBFT and SCFT under the same drift of $3.2 \%$. Furthermore, please note that the reduction rate of cumulative energy for SCFT was greater than that for SBFT, since the effect of fire altered the failure mode of SCF from ductile beam-end plastic hinging to brittle column plastic hinging. The pinching phenomenon of the hysteretic curve for SCFT as shown in Fig. 9(d) also proved this conclusion. Moreover, as is shown in Fig. 15, 
although the energy dissipations of the post-fire specimens (SBFT \& SCFT) grew steadily, they were only about a half of those of their unfired counterparts (SBF \& SCF).

In addition, the energy dissipation capacity of a structure in earthquake can be judged by the equivalent viscous damping coefficient $\left(\zeta_{\mathrm{e}}\right)[38]$, which is calculated by Eq. (3).

$$
\xi_{\mathrm{e}}=\frac{1}{2 \pi} \cdot \frac{E_{i}}{0.5\left(F_{i}^{+} D_{i}^{+}+F_{i}^{-} D_{i}^{-}\right)}=\frac{1}{2 \pi} \cdot \frac{S_{\mathrm{ABCG}}}{S_{\triangle \mathrm{OBJ}}+S_{\triangle \mathrm{OCH}}}
$$

where $E_{i}$ represents the energy dissipation for cycle $i$ and is equal to the double-line hatched area $S_{\mathrm{ABCG}}$ enclosed by the hysteretic loop, as illustrated in Fig. 12. The triangle areas of $S_{\triangle \mathrm{OBJ}}$ and $S_{\triangle \mathrm{OCH}}$ represent the elastic energy stored in an equivalent linear elastic system under static situation.

The equivalent viscous damping coefficient represents the energy dissipation capacity of each cycle normalized to the energy dissipation of an equivalent elastic cycle, which provides a satisfactory standard for pinching quantification comparison. The development of the equivalent viscous damping coefficient with the drift for all the specimens is shown in Fig. 16. The curves show that all specimens exhibited two stages in the loading process: (1) when the drift is smaller than $1.8 \%$, despite some initial fluctuation, there is slight difference between the equivalent viscous damping coefficients $\left(\zeta_{\mathrm{e}}\right)$ of the specimens, and their magnitudes were basically near 0.06 ; (2) when the drift is greater than $1.8 \%$, the $\zeta_{\mathrm{e}}$ of SCF dramatically increased to 0.15 at a drift of $3.8 \%$, whereas the increases for the $\zeta_{\mathrm{e}}$ of the rest specimens (SCFT, SBF and SBFT) were not so significant.

In summary, the energy dissipation capacity of the unfired frames increased with the rise of loading displacement, while the post-fired frames exhibited a much smaller increase when compared to their unfired counterparts. The energy dissipation capacity of all the RC frames severely decreased after being exposed to fire, especially for the specimen SCFT.

\section{Conclusions}

A series of tests were conducted to investigate the seismic performance of post-fire RC frames with different column-to-beam bending capacity ratios. The main outcomes can be summarized as following:

(1) In the fire test, the temperatures collected by thermocouples decreased with the increase of 
embedded depth at the same cross section. Profound cracks appeared on the concrete surface of all components of the RC frames. Meanwhile, concrete spalling from the slab bottom surface caused the exposure of steel reinforcements.

(2) Three different failure modes were observed in the test: (a) The brittle shear failure in the column with a main diagonal crack for the specimen SBF, which is a result of the shear force caused by the horizontal cyclical load; (b) The ductile beam-end plastic hinging failure for the specimen SCF, as a result of the yielding of longitudinal reinforcements under bending moment caused by the cyclical load; (c) The brittle column shear-bond failure for the post-fire specimens SBFT and SCFT, as a result of the shear-compression crush caused by a combination effect of both shear and compression forces. It is noted that the failure mode of the strong-column-weak-beam frame that failed in the form of beam-end ductile failure under room temperature transferred to the brittle column shear-bond failure after being exposed to fire.

(3) The hysteretic loops for the post-fire RC frames were not as full as the corresponding unfired frames and it showed remarkable pinching, which indicates that the seismic performance of the specimens decreased after exposure to fire.

(4) The external load corresponding to the first diagonal crack, the yielding and peak loads of the specimens exhibited a noticeable reduction after exposing to fire, especially for the specimen SBFT. In addition, the secant stiffness decreased with the increase of displacement, and the post-fire specimens showed higher stiffness degradation.

(5) Despite the yielding displacements for the post-fire specimens increased to a large extent, there was little difference in the ultimate displacements, so the ductility factor of the post-fire frames declined considerably.

(6) The post-fire specimens dissipated less energy with respect to their corresponding unfired specimens. In addition, the energy dissipation capacity of the unfired specimens increased with the rise of loading displacement, while the post-fire specimens displayed a smaller increase.

(7) Due to the limitation of experimental specimens, the studies on the structural response and fire resistance of damaged RC frames at elevated temperature were not conducted in this study, and should 
488 be further investigated in future researches.

489

490 Acknowledgement

491 The research described herein received financial support from the National Natural Science 492 Foundation of China (Projects No. 51778461, No. 51778496, No. 51778497 and No. 51538007). 


\section{References}

[1] GB 50011-2010. Code for seismic design of buildings. Beijing, China; 2010.

[2] Pimanmas A, Chaimahawan P. Shear strength of beam - column joint with enlarged joint area. Eng Struct. $20102010-$ 09-01; 32(9): 2529-45.

[3] Karayannis CG, Chalioris CE, Sirkelis GM. Local retrofit of exterior RC beam - column joints using thin RC jacketsAn experimental study. Earthq Eng Struct D. 2008; 37(5): 727-46.

[4] Yu JT, Liu KK, Li LZ, Wang YC, Yu KQ, Xu QF. A simplified method to predict the fire resistance of RC Beams strengthened with near-surface mounted CFRP. Compos Struct. 2018; 193(6): 1-7.

[5] Gao WY, Dai J, Teng JG. Three-level fire resistance design of FRP-strengthened RC beams. J Compos Constr. 2018; 22(3): 5018001.

[6] Yu JT, Shang XY, Lu ZD. Efficiency of externally bonded L-shaped FRP laminates in strengthening reinforcedconcrete interior beam-column joints. J Compos Constr. 2016; 20(3): 4015064.

[7] Yen JYR, Chien HK. Steel plates rehabilitated RC beam - column joints subjected to vertical cyclic loads. Constr Build Mater. 2010 2010-03-01; 24(3): 332-9.

[8] Li LZ, Cai ZW, Lu ZD, Zhang XL, Wang L. Shear performance of bolted side-plated reinforced concrete beams. Eng Struct. 2017; 144(8): 73-87.

[9] Said A, Nehdi M. Rehabilitation of RC frame joints using local steel bracing. Structure and Infrastructure Engineering: Maintenance, Management, Life-Cycle Design and Performance. 2008; 4(6): 431-47.

[10] Arioz O. Effects of elevated temperatures on properties of concrete. Fire Safety J. 2007; 42(8): 516-22.

[11] Biolzi L, Cattaneo S, Rosati G. Evaluating residual properties of thermally damaged concrete. Cement and Concrete Composites. 2008; 30(10): 907-16.

[12] Felicetti R, Gambarova PG, Meda A. Residual behavior of steel rebars and R/C sections after a fire. Constr Build Mater. 2009; 23(12): 3546-55.

[13] U LBT, Karakurt C. Properties of reinforced concrete steel rebars exposed to high temperatures. Advances in Materials Science \& Engineering. 2015; 2008(208): 4.

[14] Bingöl AF, Gül R. Residual bond strength between steel bars and concrete after elevated temperatures. Fire Safety J. 2009 2009-01-01; 44(6): 854-9.

[15] Ergün A, Kürklü G, Başpınar MS. The effects of material properties on bond strength between reinforcing bar and concrete exposed to high temperature. Constr Build Mater. 2016; 112: 691-8.

[16] Jiang CJ, Lu ZD, Li LZ. Shear performance of fire-damaged reinforced concrete beams repaired by a bolted side-plating technique. Journal of Structural Engineering - ASCE. 2017; 143(5): 4017007.

[17] Kodur VKR, Agrawal A. An approach for evaluating residual capacity of reinforced concrete beams exposed to fire. Eng Struct. 2016; 110: 293-306.

[18] Jiang CJ, Yu JT, Li LZ, Wang X, Wang L, Liao JH. Experimental study on the residual shear capacity of fire-damaged reinforced concrete frame beams and cantilevers. Fire Safety J. 2018 2018-01-01; 100: 140-56.

[19] Chen YH, Chang YF, Yao GC, Sheu MS. Experimental research on post-fire behaviour of reinforced concrete columns. Fire Safety J. 2009; 44(5): 741-8.

[20] Jau W, Huang K. A study of reinforced concrete corner columns after fire. Cement and Concrete Composites. 2008; 30(7): 622-38.

[21] Dong Y, Fan W, Wang Q, Yang B. Study on residual load-bearing capacity and reliability index of reinforced concrete 
slab post-fire. Fire Safetyence. 1996.

[22] Molkens T, Van Coile R, Gernay T. Assessment of damage and residual load bearing capacity of a concrete slab after fire: Applied reliability-based methodology. Eng Struct. 2017; 150: 969-85.

[23] Vecchio FJ, Sato JA. Thermal gradient effects in reinforced concrete frame structures. Aci Struct J. 1990; 87(3): 26275.

[24] Law A, Stern-Gottfried J, Gillie M, Rein G. The influence of travelling fires on a concrete frame. Eng Struct. 2011; 33(5): 1635-42.

[25] ASTM E119-11a. Standard methods of fire test of building construction and materials. West Conshohocken; 2011.

[26] Bisby L, Gales J, Maluk C. A contemporary review of large-scale non-standard structural fire testing. Fire Science Reviews. 2013; 2(1): 1-27.

[27] Wong Y, Ng Y. Effects of water quenching on reinforced concrete structures under fire. Hong Kong; 2011.

[28] Raouffard MM, Nishiyama M. Residual load bearing capacity of reinforced concrete frames after fire. J Adv Concr Technol. 2016 2016-01-01; 14(10): 625-33.

[29] Zhang X, Shen QQ, Zhong-Yi LI, Tang SH, Luo YS. Experimental study on fire resistance of reinforced concrete frame structure. International Conference on Mechanics and Civil Engineering; 2014, 2014.

[30] Xia M, Yu JT, Lu ZD, Zhang LW. Finite element analysis of concrete frames after fire with fiber model. Applied Mechanics \& Materials. 2012; 193-194(1): 372-8.

[31] Kamath P, Sharma UK, Kumar V, Bhargava P, Usmani A, Singh B, et al. Full-scale fire test on an earthquake-damaged reinforced concrete frame. Fire Safety J. 2015; 73(4): 1-19.

[32] Shah AH, Sharma UK, Bhargava P. Outcomes of a major research on full scale testing of RC frames in post earthquake fire. Constr Build Mater. 2017.

[33] Xiao JZ, Li J, Huang ZF. Fire response of high-performance concrete frames and their post-fire seismic performance. Aci Struct J. 2008; 105(5): 531-40.

[34] Park R. Evaluation of ductility of structures and structural assemblages from laboratory testing. Bulletin of the New Zealand National Society for Earthquake Engineering. 1989; 22(3): 155-6.

[35]Li L. New partial interaction models for bolted-side-plated reinforced concrete beams. PhD dissertation. Pokfulam Road, Hong Kong: The University of Hong Kong; 2013.

[36] Al-Salloum YA, Almusallam TH, Alsayed SH, Siddiqui NA. Seismic behavior of as-built, ACI-complying, and CFRPrepaired exterior RC beam-column joints. J Compos Constr. 2011; 15(4): 522-34.

[37] Priestley MJN, Macrae GA. Seismic tests of precast beam-to-column joint subassemblages with unbonded tendons. Pci J. 1996; 41(1): 64-81.

[38] Priestley MJN, Seible F, Calvi GM. Seismic design and retrofit of bridges: Wiley-Interscience; 2000. 
Table 1 Design parameters of specimens

\begin{tabular}{|c|c|c|c|c|c|c|c|c|c|}
\hline \multirow[t]{2}{*}{ Specimen } & \multirow[t]{2}{*}{ Fired or not } & \multicolumn{2}{|c|}{ Sectional size $(\mathrm{mm})$} & \multicolumn{2}{|c|}{ Reinforcement } & \multicolumn{2}{|c|}{ Bending capacity $(\mathrm{kN} \cdot \mathrm{m})$} & \multirow{2}{*}{$\eta=\frac{M_{\mathrm{c}}}{M_{\mathrm{b}}}$} & \multirow{2}{*}{ Type of frame } \\
\hline & & Column & Beam & Column & Beam & Column $\left(M_{\mathrm{c}}\right)$ & $\operatorname{Beam}\left(M_{\mathrm{b}}\right)$ & & \\
\hline SBF & & $250 \times 250$ & & & 3D16 & 56.0 & 85.2 & 0.7 & \\
\hline SBFT & Fired & $250 \times 250$ & $150 \times 350$ & $8 \mathrm{D} 16$ & 3D16 & 56.0 & 85.2 & 0.7 & Strong-Beam \\
\hline SCF & Unfired & $250 \times 250$ & $120 \times 250$ & 8D16 & 2D14 & 56.0 & 35.2 & 1.6 & Strong-Column \\
\hline SCFT & Fired & $250 \times 250$ & $120 \times 250$ & 8D16 & 2D14 & 56.0 & 35.2 & 1.6 & Strong-Column \\
\hline
\end{tabular}

Table 2 Mix proportions of the concrete

\begin{tabular}{llll}
\hline Sample & Specification & Unit weight $\left(\mathrm{kg} / \mathrm{m}^{3}\right)$ & Mixture ratio \\
\hline Cement & P.O. 42.5 & 286 & 1.00 \\
Fine aggregates & Medium sands & 747 & 2.61 \\
Coarse aggregates & Particle sizes $(2-25 \mathrm{~mm})$ & 1075 & 3.76 \\
Water & Purified water & 175 & 0.61 \\
Additives & LX-3 & 6.07 & 0.02 \\
Fly ash & Grade II & 71 & 0.25 \\
\hline
\end{tabular}

Note:

1) Cement: P.O. 42.5 (Chinese cement grading system) ordinary Portland cement from Jinfeng City, and $28 \mathrm{~d}$ compressive strength of the cement paste is $42.5 \mathrm{MPa}$.

2) Fly ash: Grade II (Chinese fly ash grading system) fly ash of Jiangsu Huawang brand.

3) Additives: LX-3 produced by Longxi Co., Shanghai city, China.

Table 3 Mechanical properties of reinforcement

\begin{tabular}{llll}
\hline Sample & Diameter $(\mathrm{mm})$ & Yield strength $(\mathrm{MPa})$ & Ultimate strength $(\mathrm{MPa})$ \\
\hline R6 & 6 & 413.4 & 510.2 \\
D14 & 14 & 589.9 & 701.7 \\
D16 & 16 & 484.0 & 597.3 \\
D20 & 20 & 446.5 & 582.3 \\
\hline
\end{tabular}

Table 4 Failure modes, ultimate loads, and ductility factors

\begin{tabular}{llllllll}
\hline Specimen & Fired or not & Failure mode & $P_{\mathrm{u}}(\mathrm{kN})$ & $\Delta_{\mathrm{y}}(\mathrm{mm})$ & $\Delta_{\mathrm{u}}(\mathrm{mm})$ & $\mu=\Delta_{\mathrm{u}} / \Delta_{\mathrm{y}}$ & $K_{\mathrm{e}}(\mathrm{kN} / \mathrm{mm})$ \\
\hline SBF & Unfired & Column-end shear failure & 262.0 & 21.6 & 56.4 & 2.6 & 12.2 \\
SBFT & Fired & Column shear-bond failure & $164.5(-37 \%)$ & 24.9 & 43.6 & $1.8(-33 \%)$ & $6.6(-45 \%)$ \\
SCF & Unfired & Beam-end plastic hinging & 191.7 & 20.4 & 58.9 & 2.9 & 9.4 \\
SCFT & Fired & Column shear-bond failure & $154.2(-20 \%)$ & 34.0 & 59.1 & $1.8(-39 \%)$ & $4.6(-51 \%)$ \\
\hline
\end{tabular}

Note:

The figures in the parentheses are the reduction percentages of the parameters of the post-fire frames compared to their unfired counterparts. 


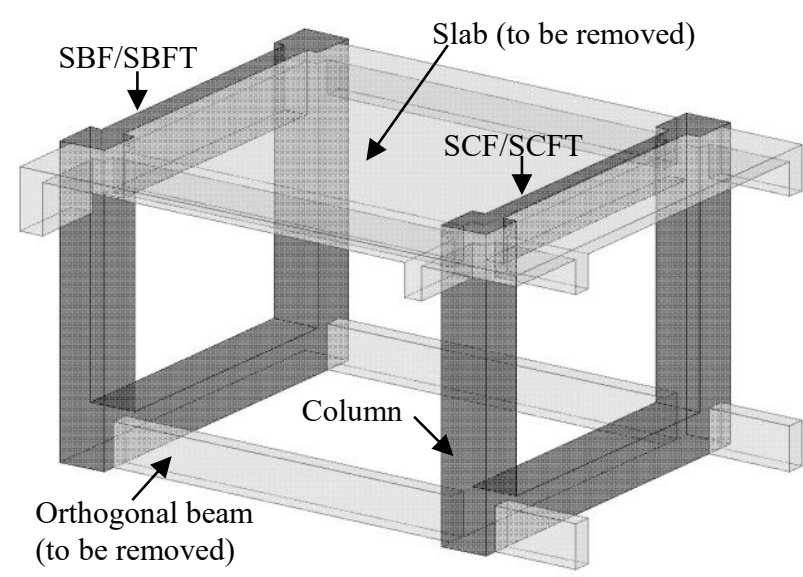

(a) $3 \mathrm{D}$ view of the spatial $\mathrm{RC}$ frame

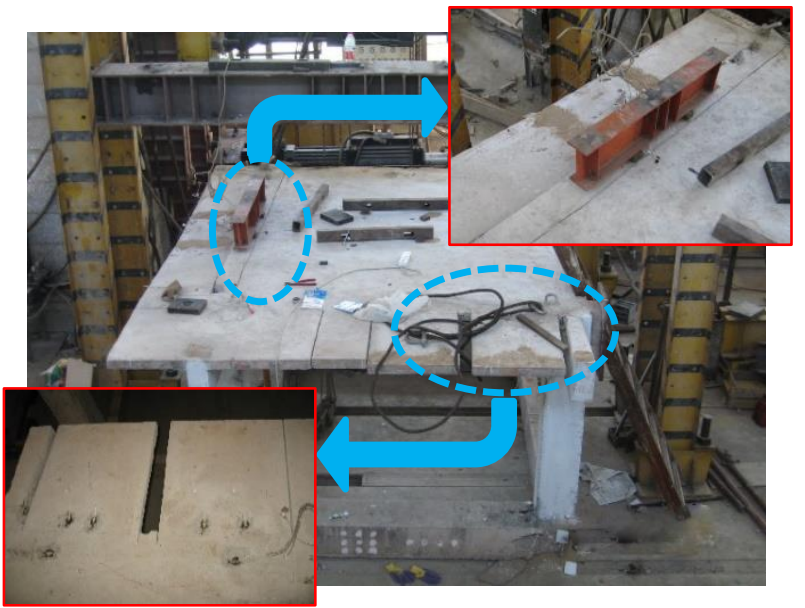

(b) removing process of slab and orthogonal beams

Fig. 1 General view of the spatial RC frames before being cut to planar frames 


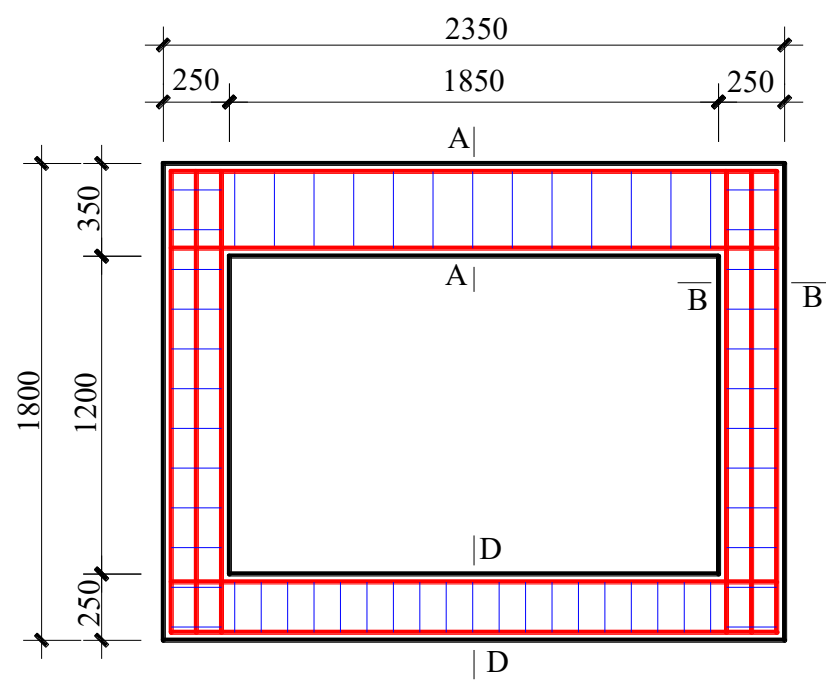

(a) Specimens SBF and SBFT

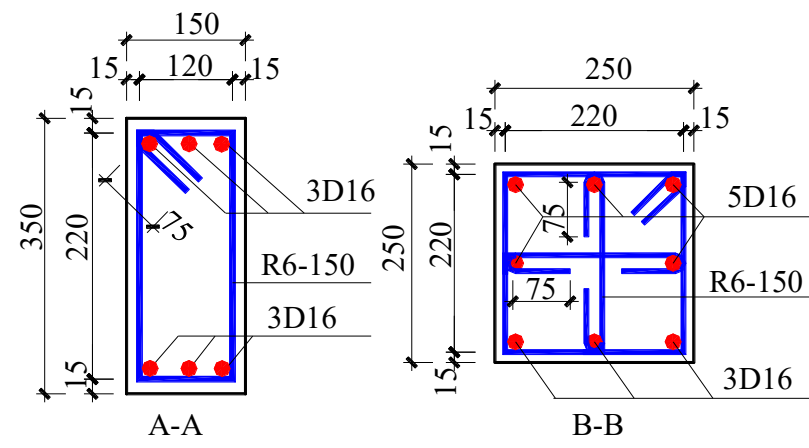

(c) Beam and column cross sectional dimension

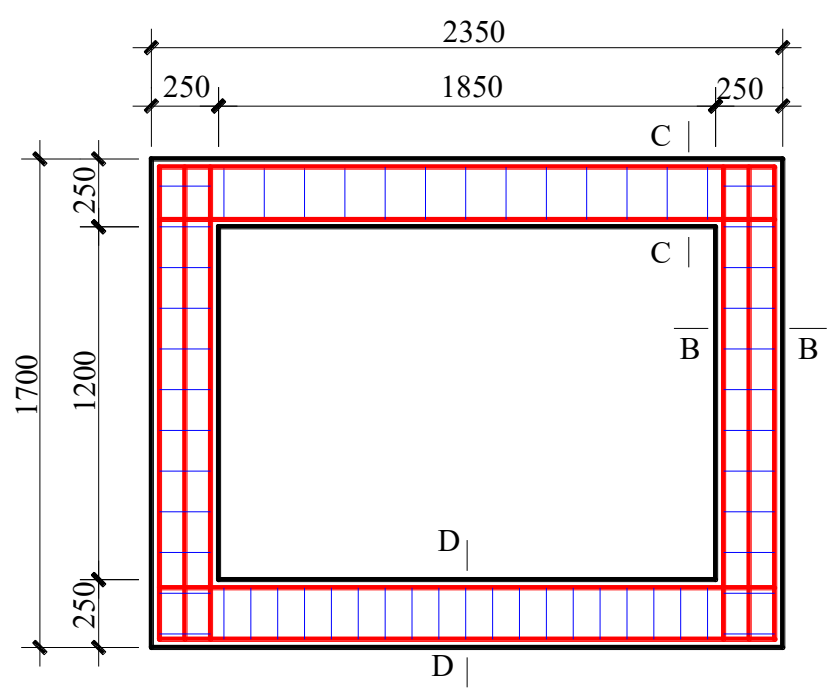

(b) Specimens SCF and SCFT
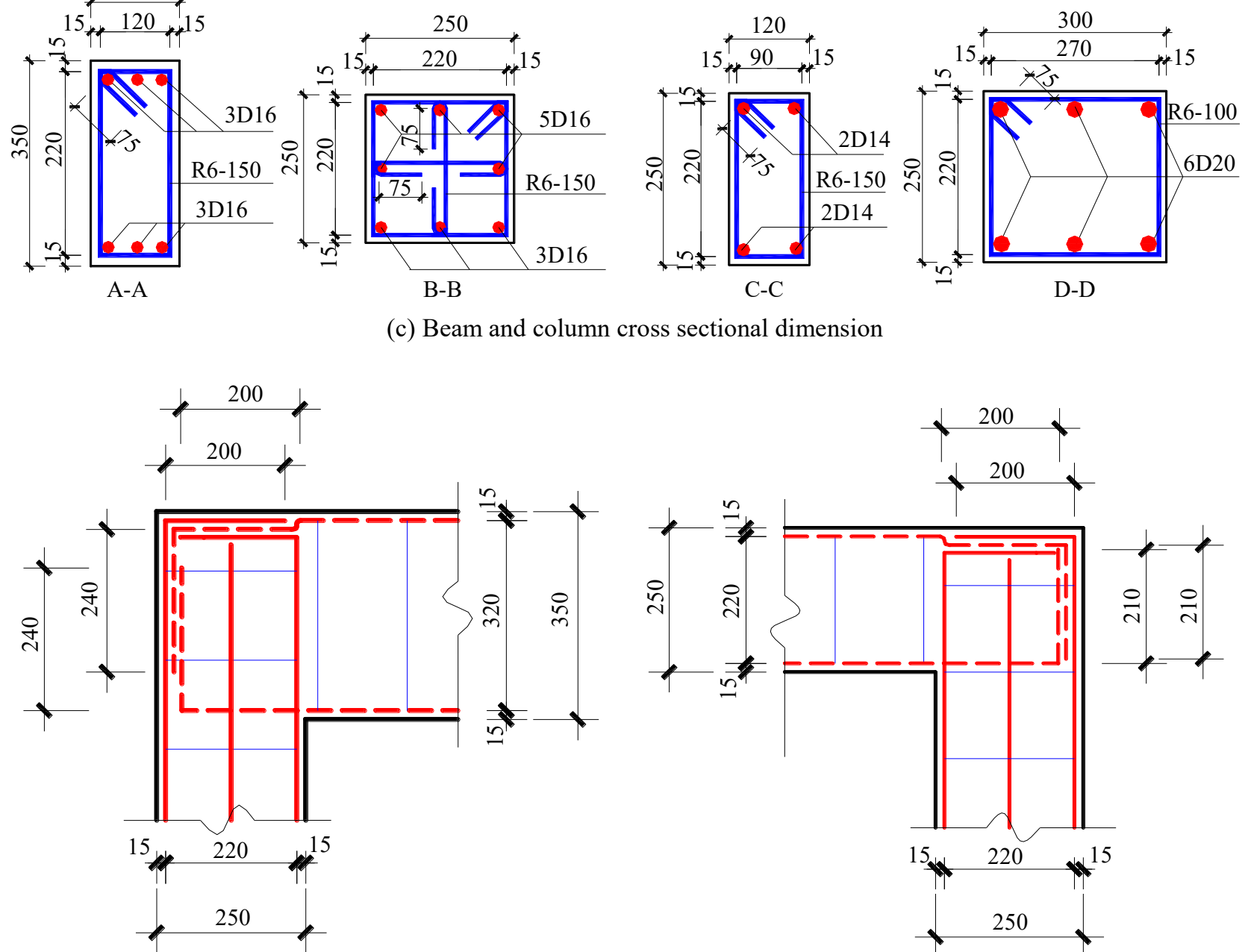

(d) Hook anchorage of joint zone for SBF and SBFT

(e) Reinforcements details of joint zone for SCF and SCFT 


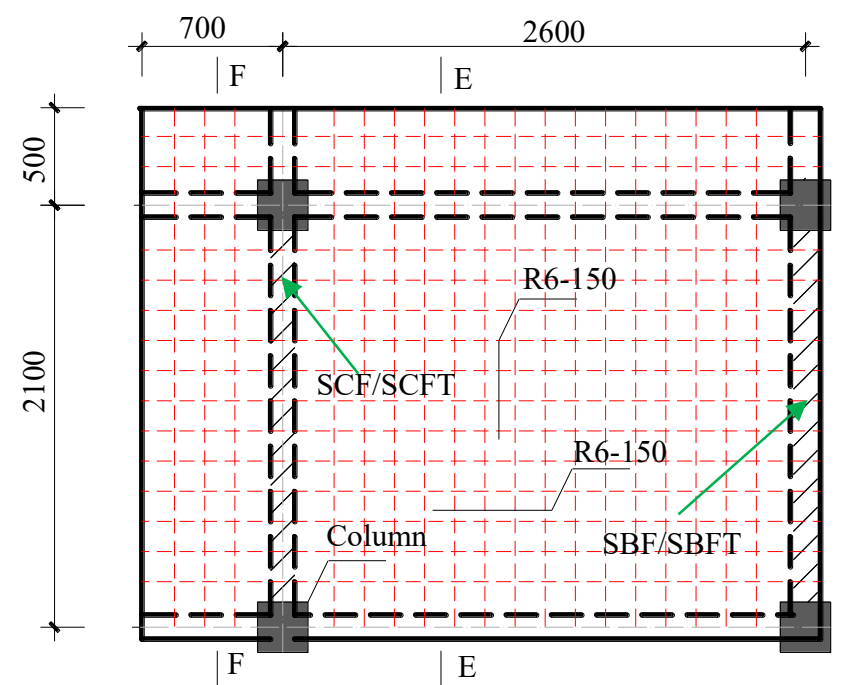

(f) Top view of reinforcement details of floor slab

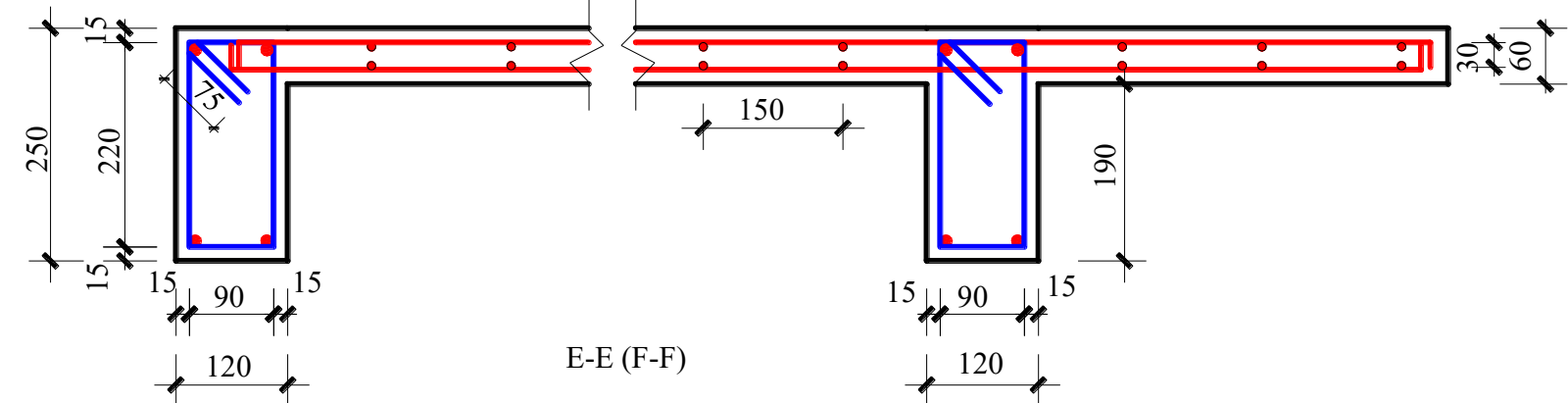

(g) Section view and reinforcements details of the slab and orthogonal beam (section E-E and F-F)

Fig. 2 Dimensions and reinforcement details (dimensions in $\mathrm{mm}$ ) 


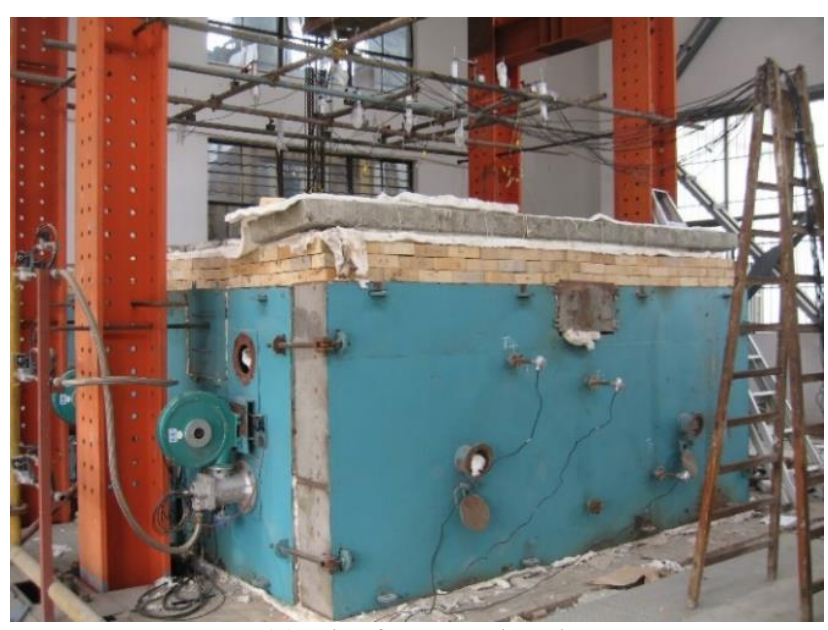

(a) The furnace chamber

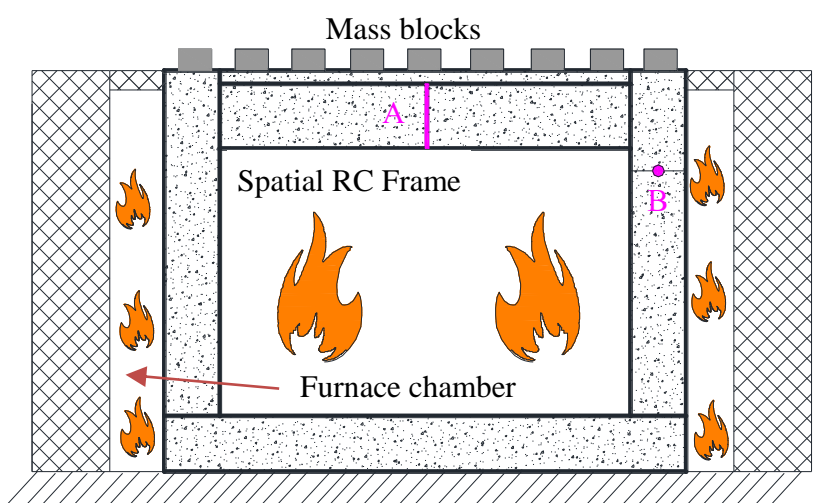

(c) Schematic diagram of fire test

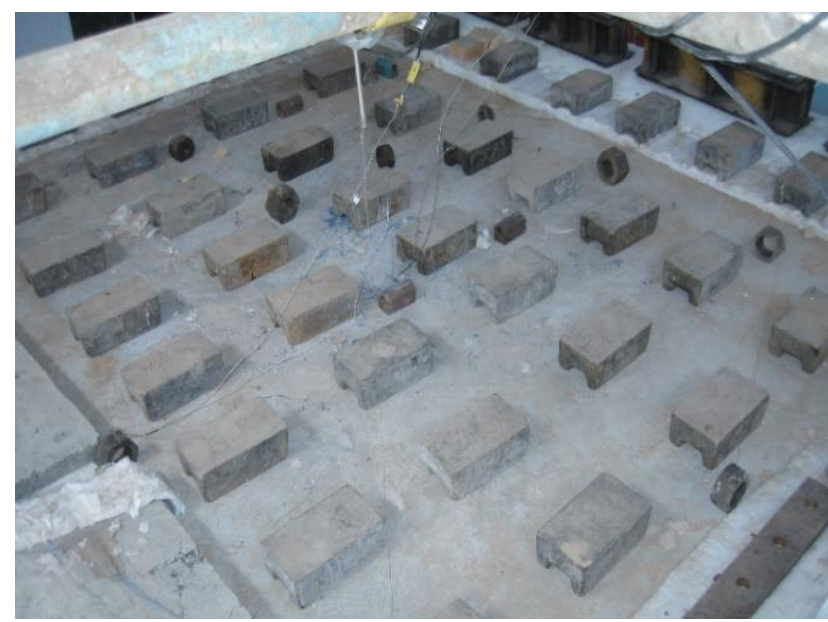

(b) Uniformly distributed load
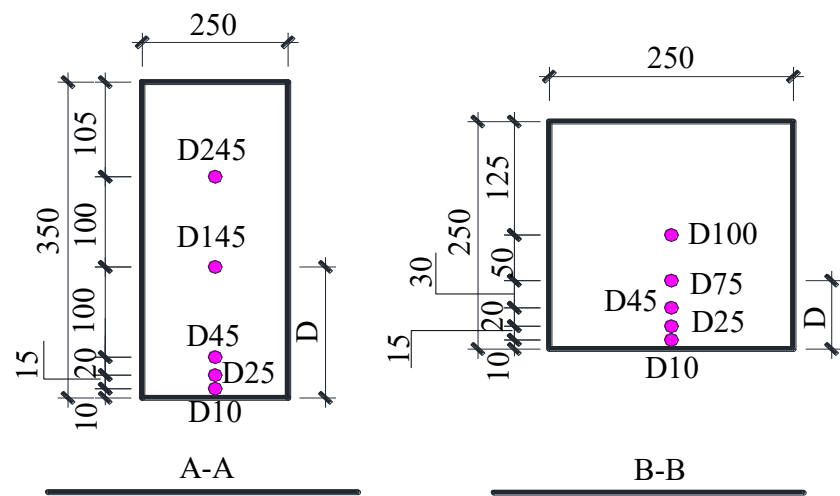

(d) Thermocouples in the beam mid-span and column

Fig. 3 General view of the fire test (dimensions in $\mathrm{mm}$ ) 


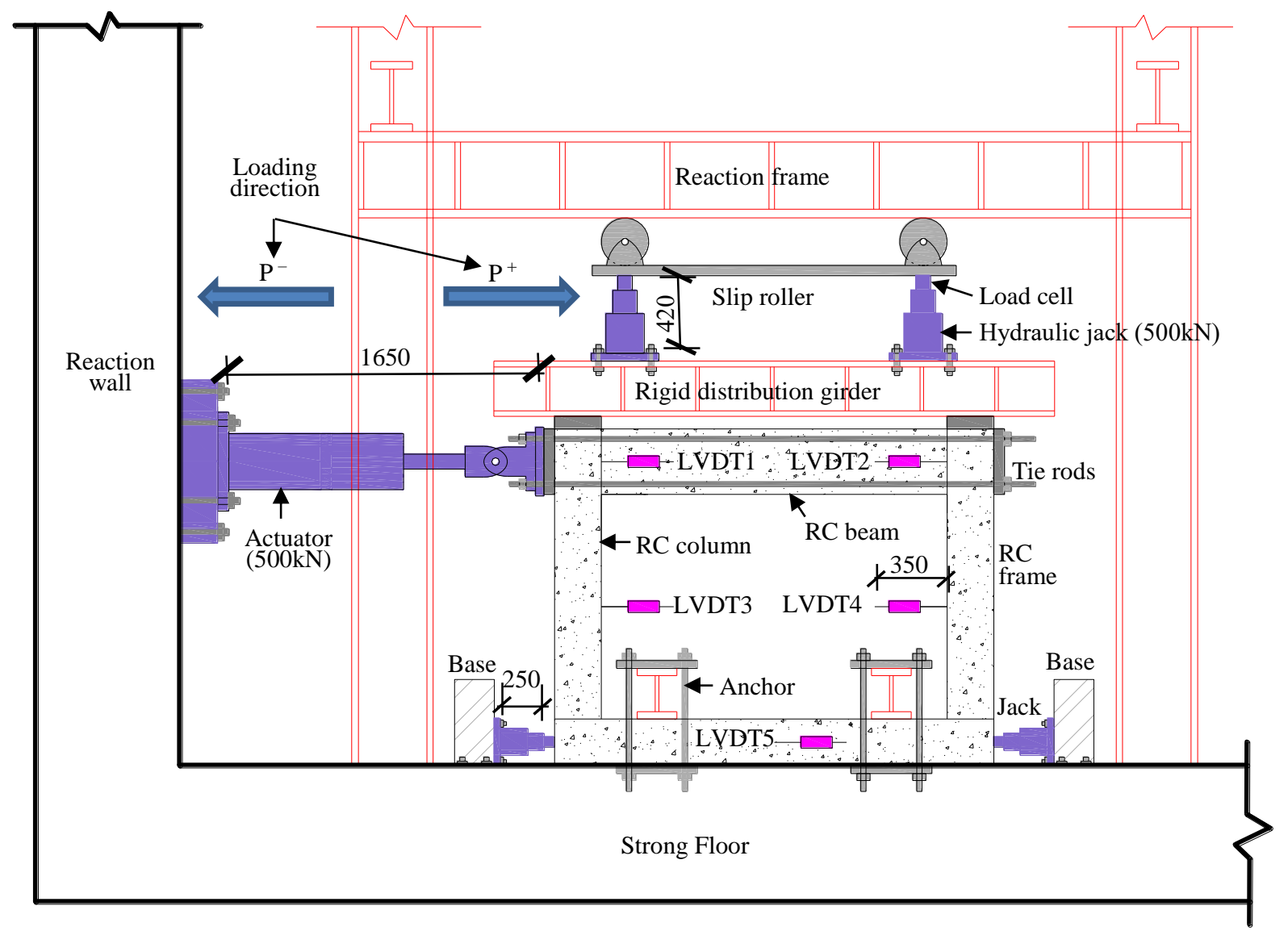

Fig. 4 Over view of test setup and instrumentation (dimensions in $\mathrm{mm}$ ) 


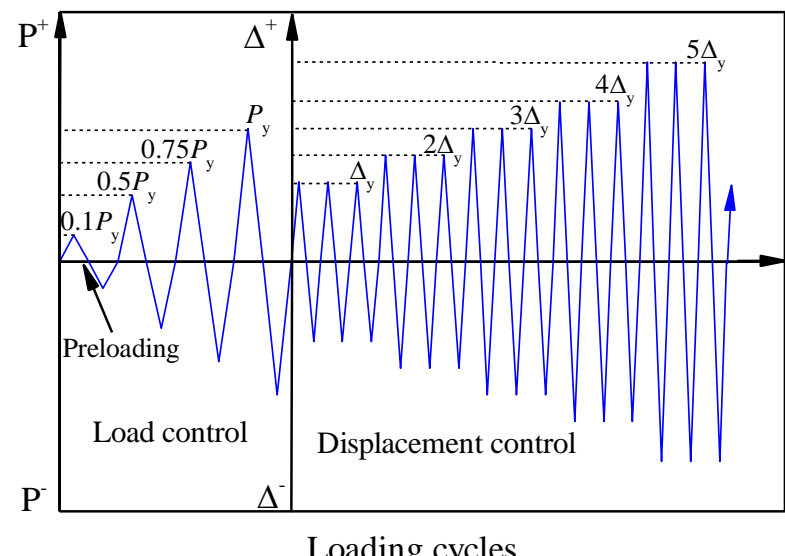

Fig. 5 Load protocol for the reversed cyclic load test 


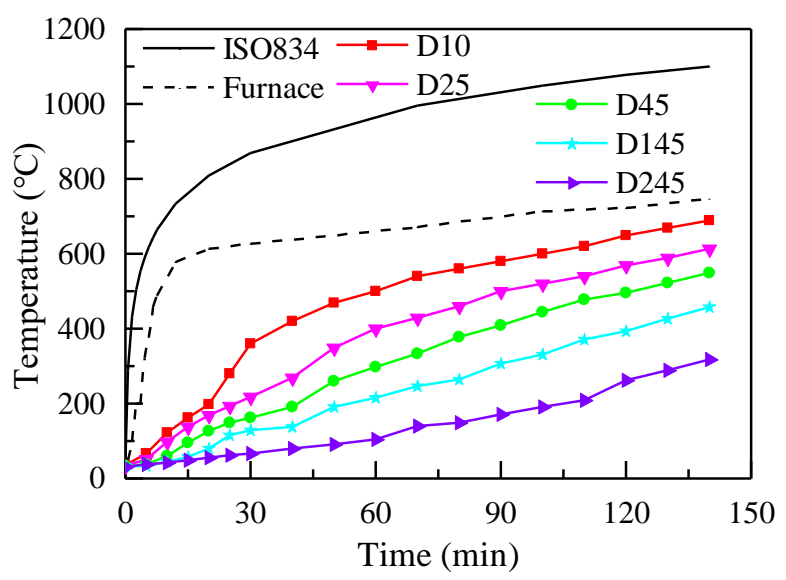

(a) For thermocouples in the SBFT beam mid-span and the furnace

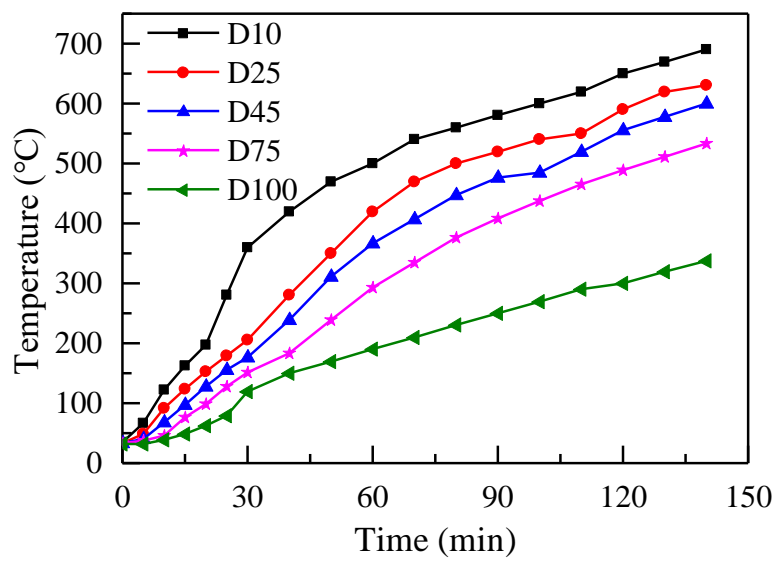

(b) For thermocouples in the SCFT beam mid-span

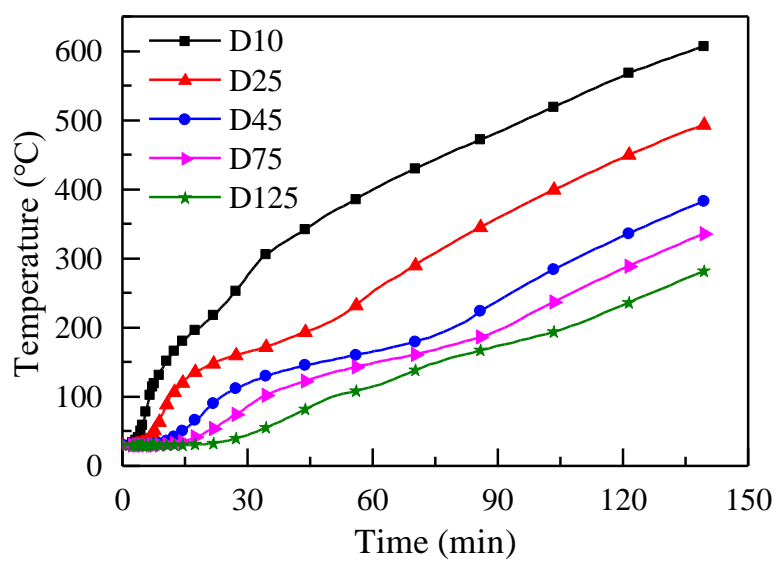

(c) For thermocouples in the column

Fig. 6 Temperature-time curves of the spatial RC frame under fire 


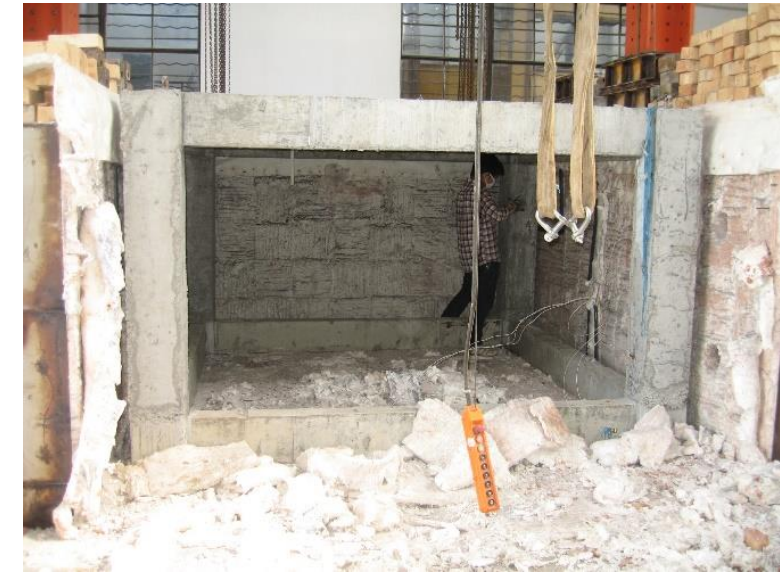

(a) The post-fire spatial frame in the furnace

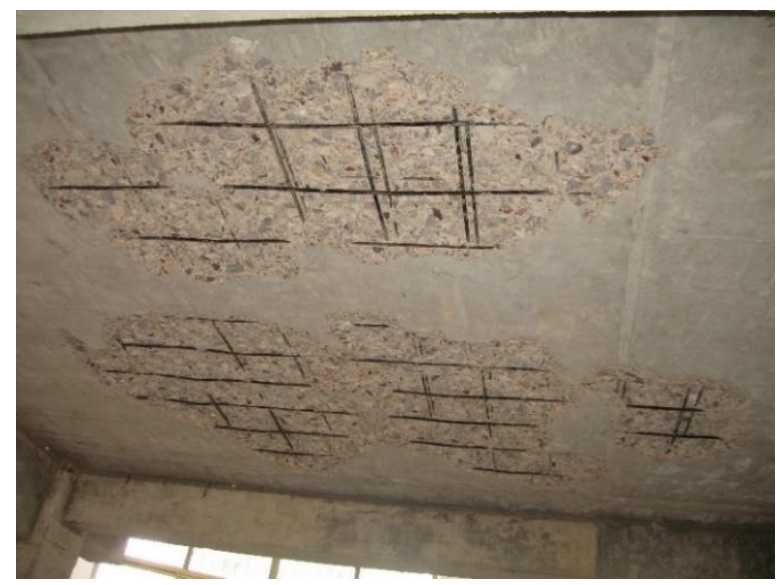

(c) The slab bottom after fire

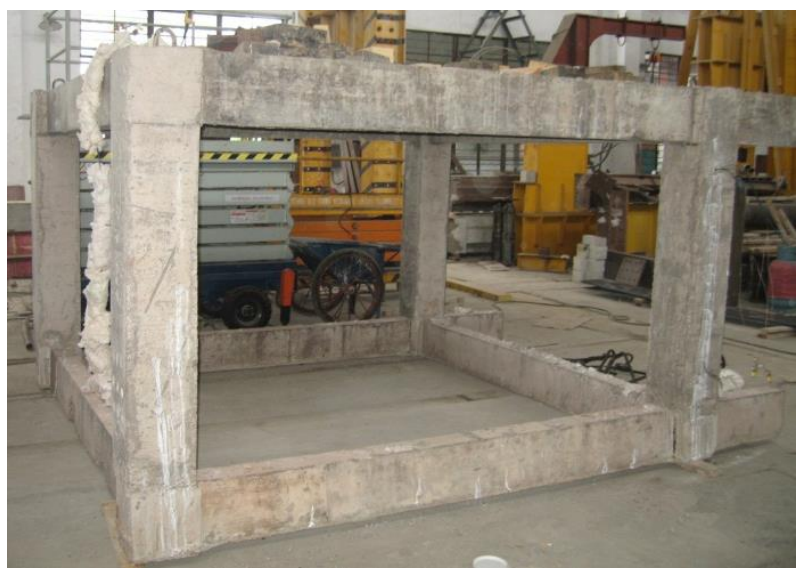

(b) The spatial RC frame after fire exposure
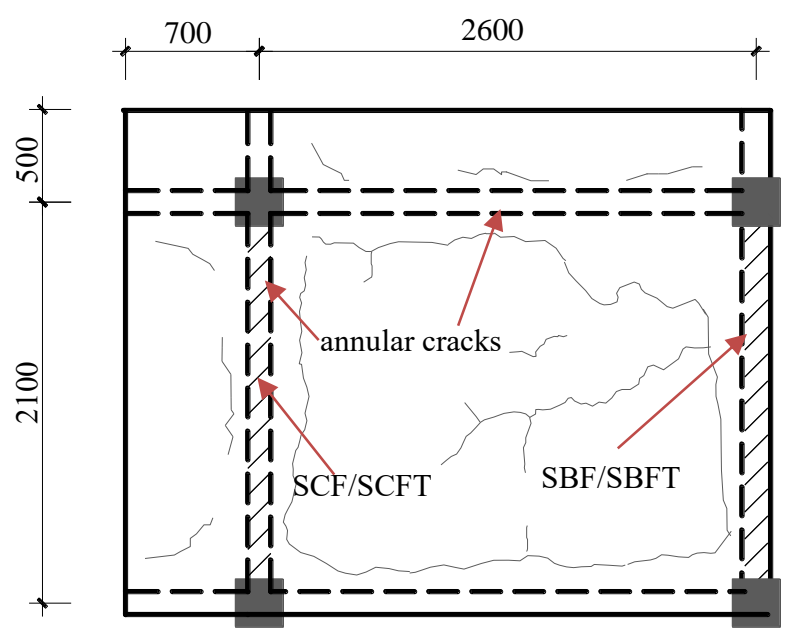

(d) Sketch of annular cracks on the slab surface after fire

Fig. 7 View of the RC frames after fire (dimensions in $\mathrm{mm}$ ) 


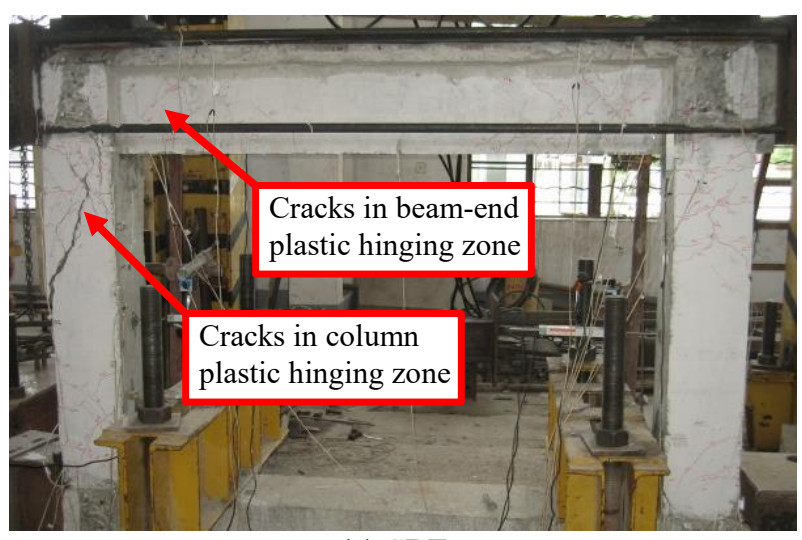

(a) SBF

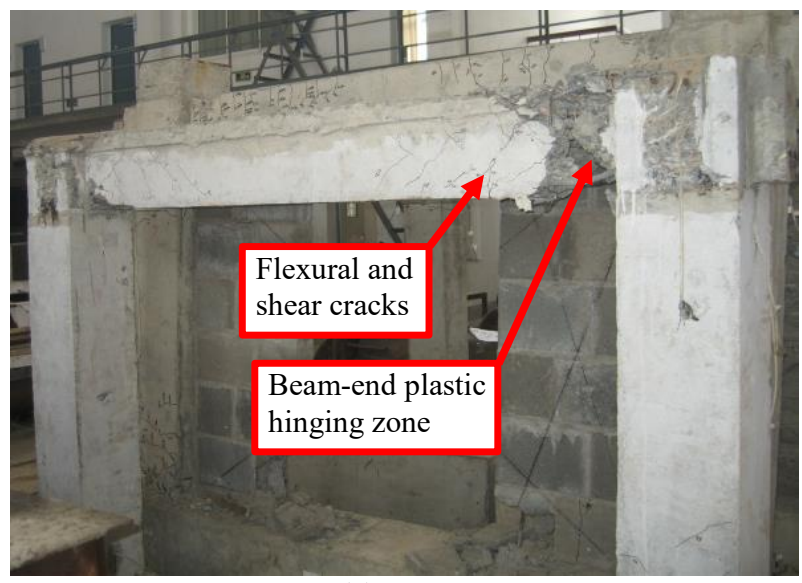

(c) SCF

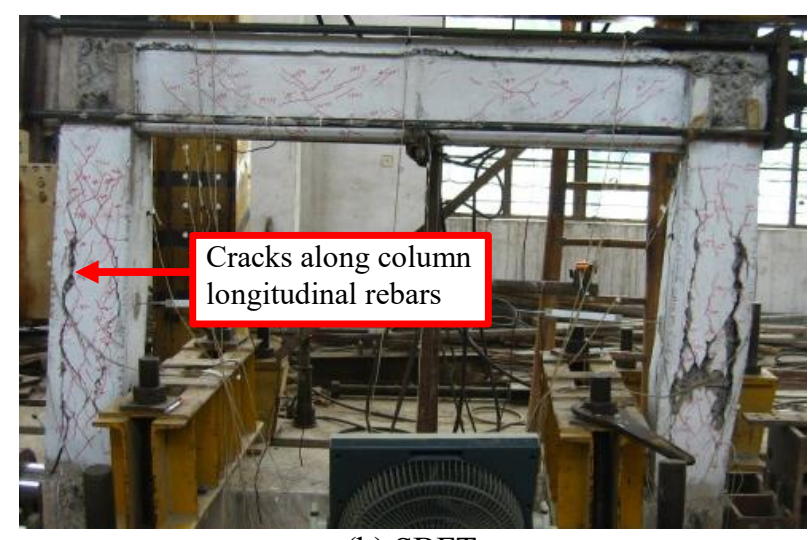

(b) SBFT

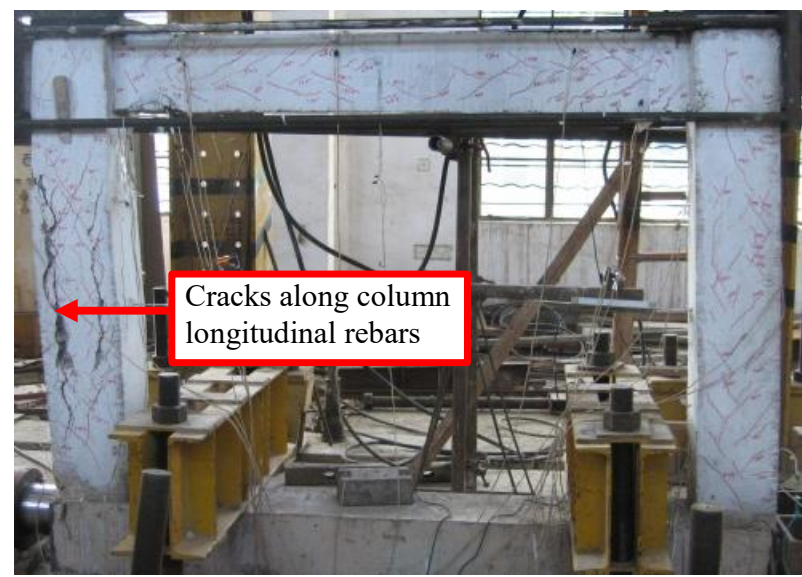

(d) SCFT

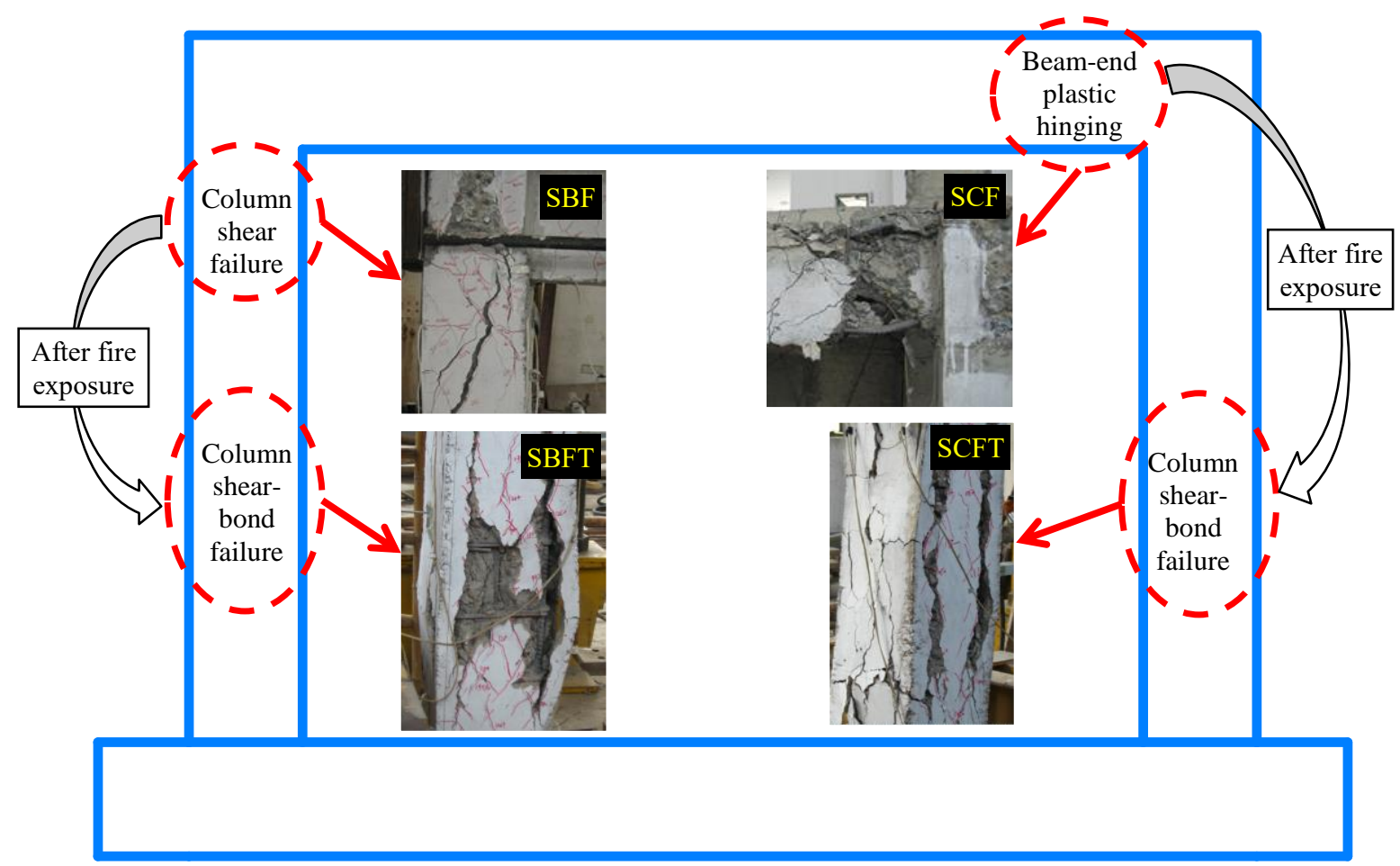

(e) view of transformation of failure mode

Fig. 8 The failure modes of RC frames 
Displacement (mm)

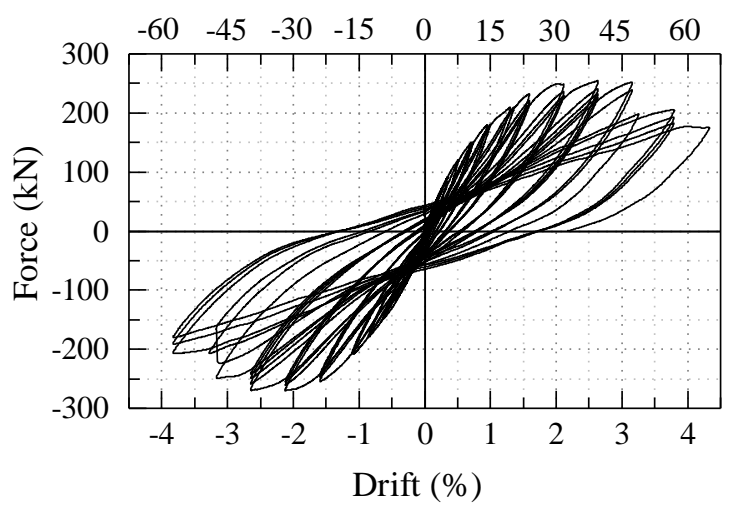

(a) Specimen $\mathrm{SBF}$

Displacement ( $\mathrm{mm})$

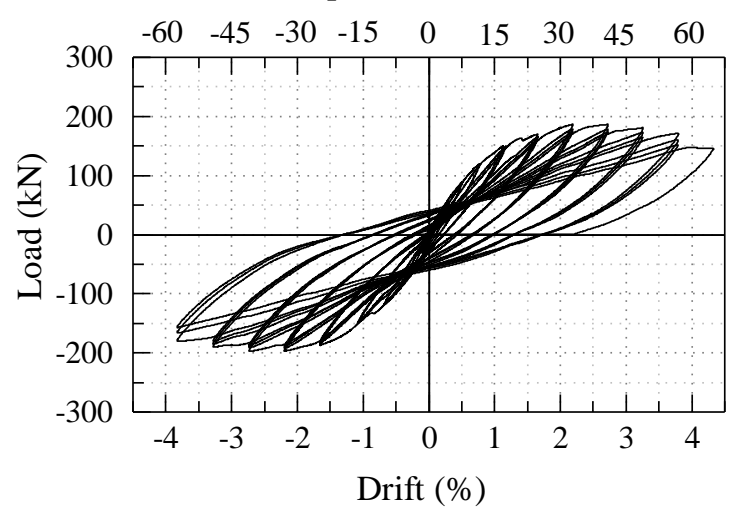

(c) Specimen SCF
Displacement (mm)

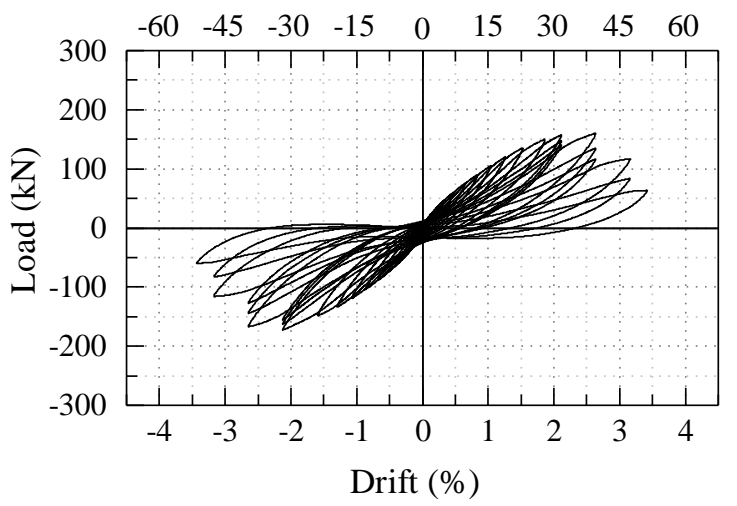

(b) Specimen SBFT

Displacement (mm)

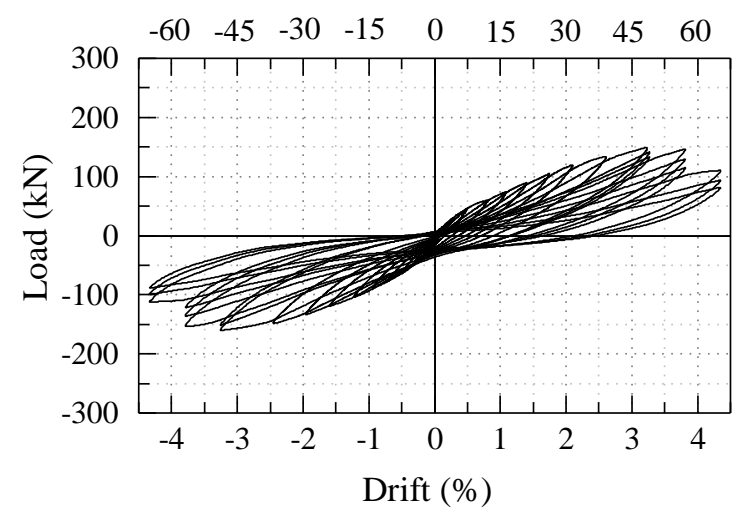

(d) Specimen SCFT

Fig. 9 Force-displacement hysteretic responses

Displacement (mm)

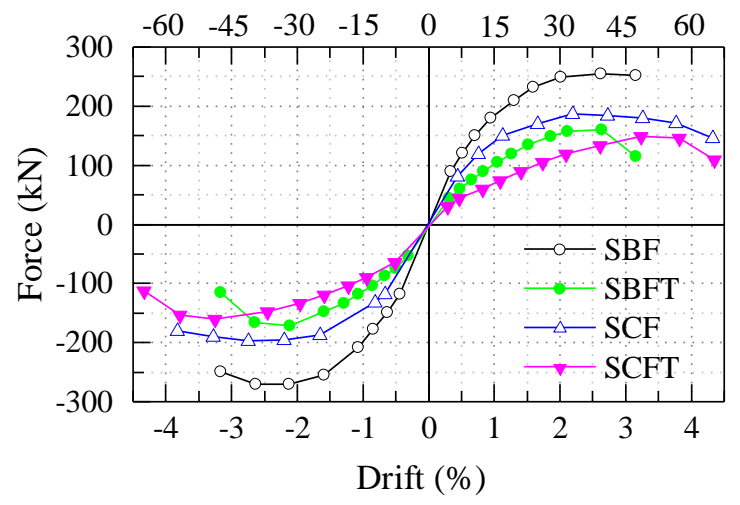

Fig. 10 Comparison of force-displacement envelope curves 


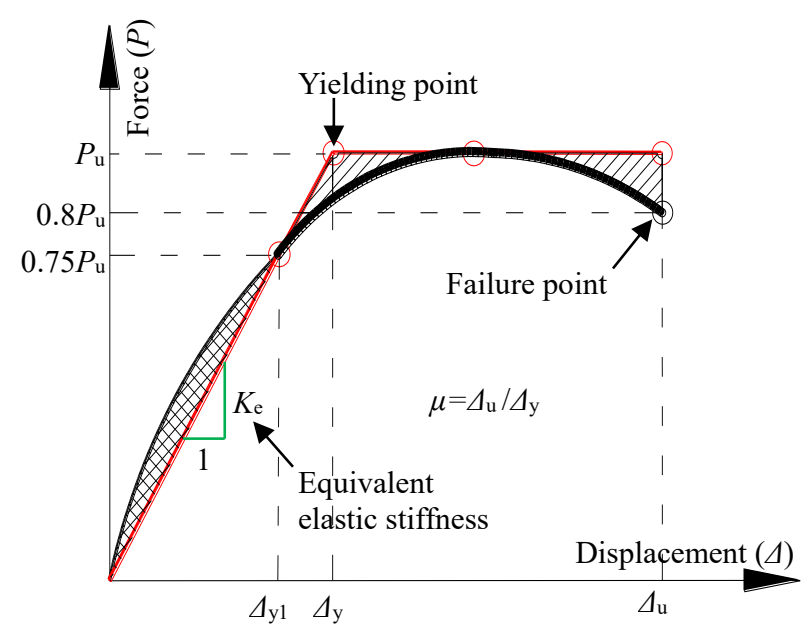

Fig. 11 Characteristic points on force-displacement curve

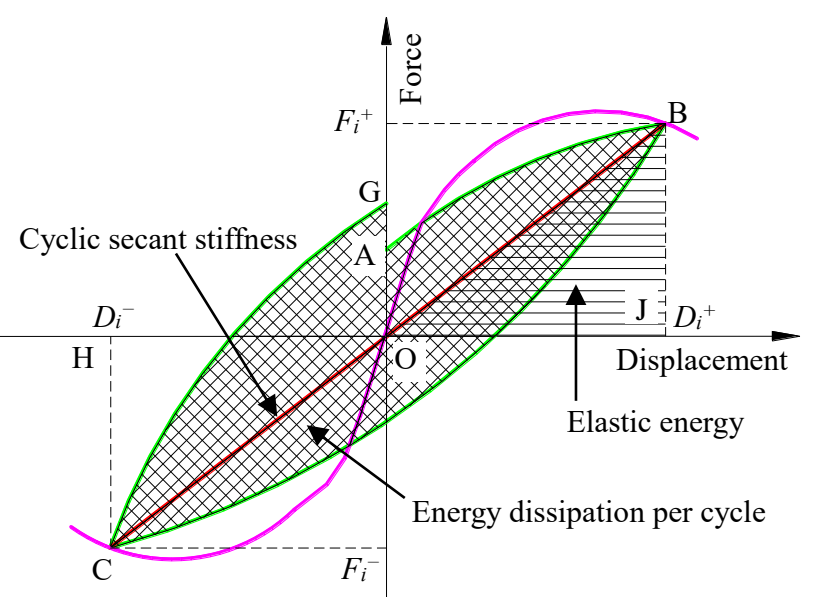

Fig. 12 Calculation model of energy dissipation, secant stiffness and equivalent viscous damping coefficient

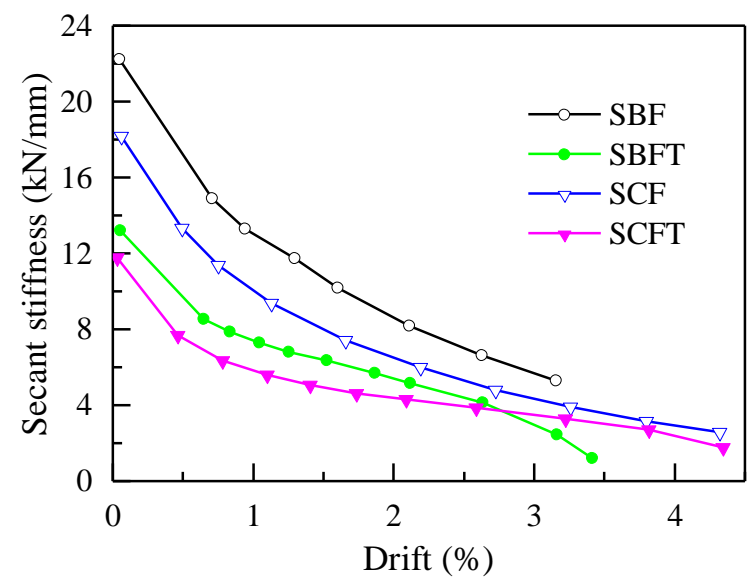

Fig. 13 Comparison of the degradation of peak-to-peak secant stiffness 


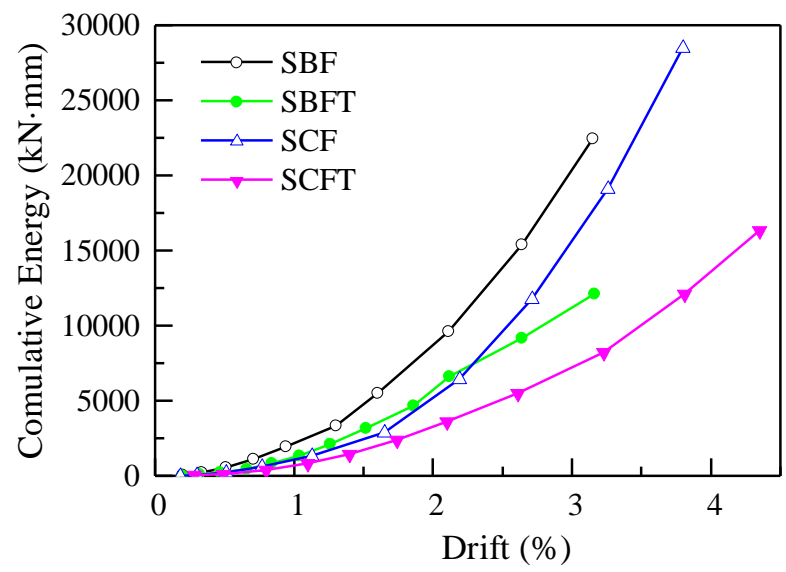

Fig. 14 Cumulative energy dissipation

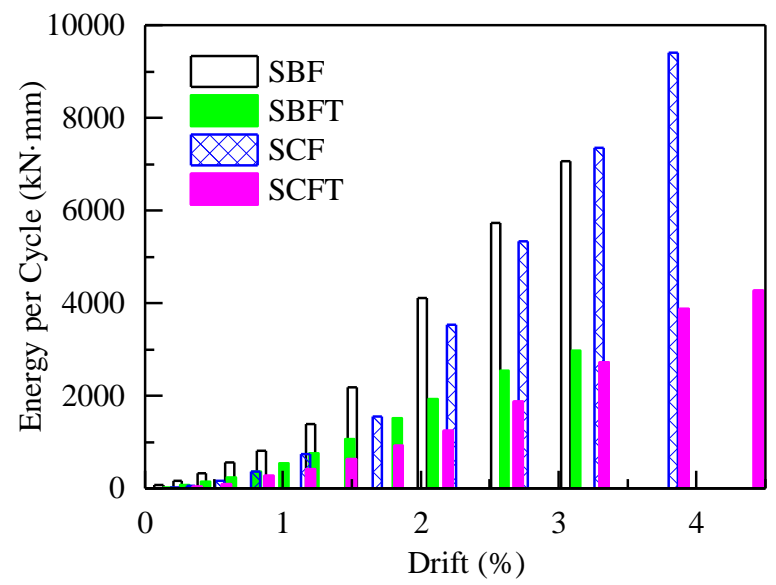

Fig. 15 Energy dissipation per cycle

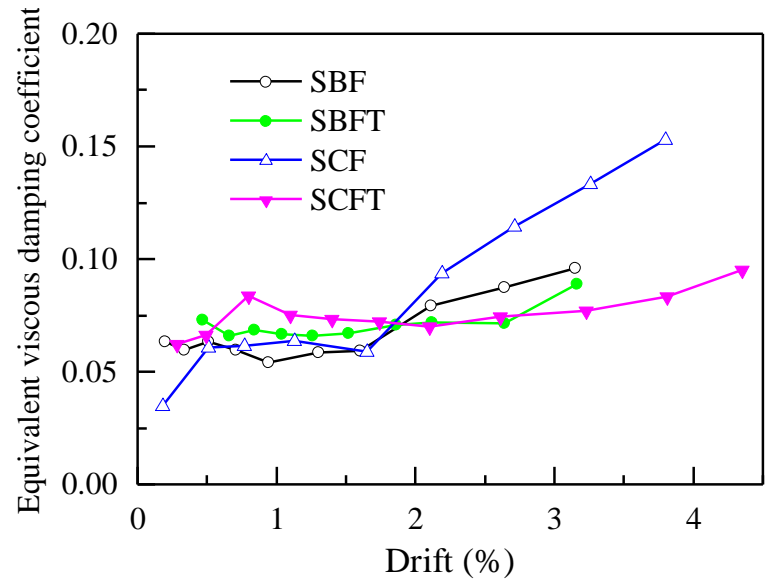

Fig. 16 Equivalent viscous damping coefficient versus drift chart 